This PDF is a selection from a published volume from the National Bureau of Economic Research

Volume Title: Frontiers in Health Policy Research, Volume 7

Volume Author/Editor: David M. Cutler and Alan M. Garber, editors

Volume Publisher: MIT Press

Volume ISBN: 0-262-03325-9

Volume URL: http://www.nber.org/books/cutl04-1

Conference Date: June 6, 2003

Publication Date: July 2004

Title: An Economic Analysis of Health Plan Conversions: Are They in the Public Interest?

Author: Nancy Dean Beaulieu

URL: http://www.nber.org/chapters/c9872 


\title{
An Economic Analysis of Health Plan Conversions: Are They in the Public Interest?
}

\author{
Nancy Dean Beaulieu, Harvard Business School and NBER
}

\section{Executive Summary}

Over the last decade, managed-care companies have been consolidating on both a regional and national scale. More recently, nonprofit health plans have been converting to for-profit status, and this conversion has frequently occurred as a step to facilitate merger or acquisition with a for-profit company. Some industry observers attribute these managed-care marketplace trends to an industry shakeout resulting from increased competition in the sector. At the same time, these perceived competitive pressures have led to questions about the long-run viability of nonprofit health plans. Furthermore, some industry and government leaders believe that some nonprofits are already conducting themselves like for-profit health plans and question the state premium tax exemption ordinarily accorded to such plans. This paper examines related health policy issues through the lens of a case study of the proposed conversion of the CareFirst Blue Cross Blue Shield company to a for-profit public-stock company and its merger with the Wellpoint Corporation. Company executives and board members argued that CareFirst lacked access to sufficient capital and faced serious threats to its viability as a financially healthy nonprofit health care company. They also argued that CareFirst and its beneficiaries would benefit from merger through enhanced economies of scale and product-line extensions. Critics of the proposed conversion and merger raised concerns about the adverse impacts on access to care, coverage availability, quality of care, safety-net providers, and the cost of health insurance. Analyses demonstrate that CareFirst wields substantial market power in its local market, that it is unlikely to realize cost savings through expanded economies of scale, and that access to capital concerns are largely driven by the perceived need for further expansion through merger and acquisition. Although it is impossible to predict future changes in quality of care for CareFirst, analyses suggest that quality appears to be somewhat lower in forprofit national managed-care companies. Additional research is needed to assess the viability of true nonprofits, the potential effects of nonprofits and for-profit national managed-care plans on the evolution of local insurance and provider markets, and methods for effective oversight of nonprofit health plans. 


\section{Introduction}

In 1994, the Blue Cross and Blue Shield (BCBS) Association changed its bylaws to allow members to convert to public-stock companies. This touched off a streak of conversions and health plan combinations. To date, fourteen BCBS plans have converted to for-profit plans and a few more have conversions pending. Consolidation has also occurred among BCBS plans; in 1996, there were sixty-three BCBS plans in operation; in 2003, there were forty-one. In many instances, BCBS plans have converted with the explicit intention of being acquired or of merging with another firm; hence conversions and consolidation are intertwined. This situation has certainly been the case for two BCBS plans that have led the consolidation trend. Anthem, Inc. is a publicly traded BCBS plan that was built up through the acquisition of exclusive BCBS licenses in nine states. WellPoint, Inc. began with the conversion of the California Blue Cross Association and has grown to the largest BCBS company, with operations in California, Georgia, and Missouri. ${ }^{1}$ Regional consolidation has also occurred among nonprofit BCBS plans (for example, the Regence Group with operations in Washington, Oregon, Utah, and Idaho).

These changes among BCBS Association members have occurred against a backdrop of the growing presence of national managed-care companies and for-profit health plans in the health maintenance organization (HMO) industry. As shown in figures 5.1 and 5.2, HMO enrollment increased 173 percent from 1987 to 2001 . Nearly three-quarters of the increase is attributable to enrollment growth in for-profit health plans; 50 percent of the enrollment growth occurred in for-profit national managed-care plans. Some industry analysts have argued that the rise of national managed-care companies has precipitated conversion and consolidation among BCBS plans.

Each of the conversion cases is unique. Local health plan markets are unique, and so the health plans that operate in them evolve with a unique history. Thus, the evaluations of specific conversion petitions (and possible acquisitions and mergers) must take into account factors unique to each market. Some policy issues are common to all conversions, however, and in this paper I develop a framework for analyzing these issues and clarifying the trade-offs faced by policy makers.

Following a general discussion of the policy issues and the development of an analytic framework, I present a case study analysis of a particular conversion petition. In January 2002, the CareFirst Corporation 


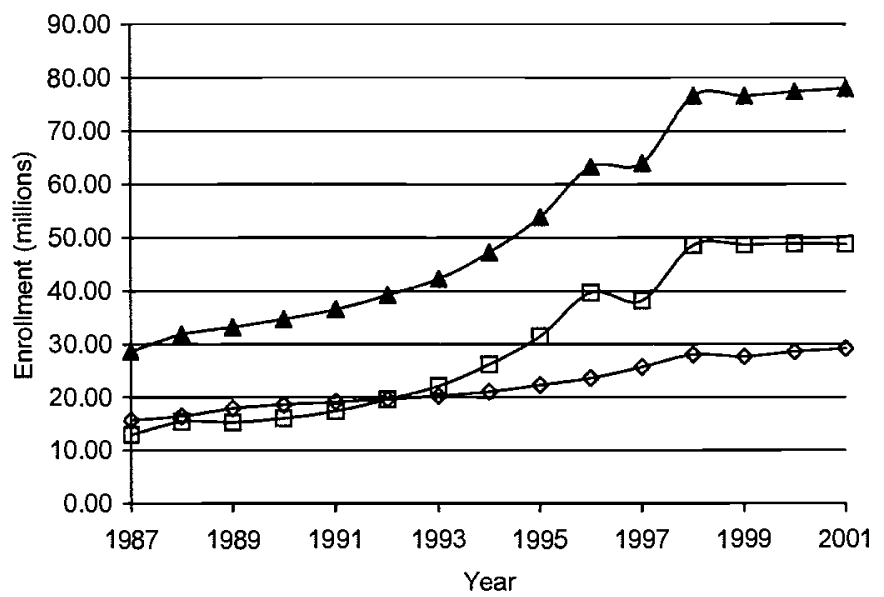

$\multimap$ Non-profit enroliment $\square-$ For-profit enrollment $\rightarrow-$ Total enrollment

Figure 5.1

HMO enrollment by tax status

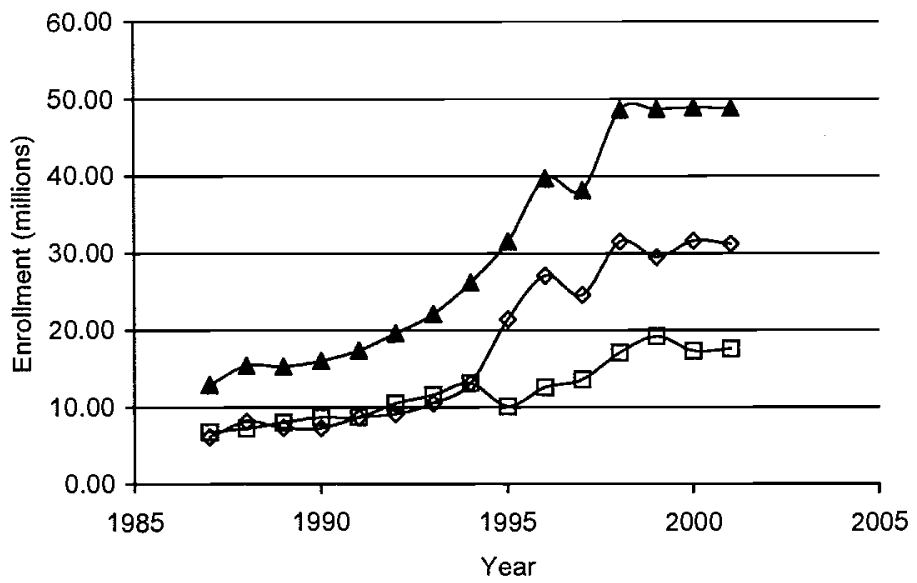

$\leadsto$ For-profit national $\varangle$ For-profit local or regional $\rightarrow-$ Total for-profit enrollment

\section{Figure 5.2}

HMO enrollment in national versus local or regional for-profit health plans 
filed applications to convert to public-stock ownership with insurance commissioners in the states of Delaware and Maryland, and in the District of Columbia. CareFirst's conversion application was explicitly linked to subsequent acquisition by Wellpoint Inc. I present analyses that were conducted for the public advocacy organization, D.C. Appleseeds, to support its participation in the formal proceedings in Washington, D.C. At the end of this paper, I discuss the information gaps that plague research and policy analysis on this topic, opportunities for health economists to contribute to policy in this arena, and the limitations and generalizability of my case study research.

\section{Policy Issues in Health Plan Conversions}

Blue Cross and Blue Shield plans are not the only health plans to convert to public-stock ownership. The BCBS conversion petitions have sparked the most public debate however, partly because of the special circumstances in which they were created and because their conversion typically requires a formal determination by a regulatory official; some conversions even require legislation. This paper deals specifically with BCBS conversions; however, several of the health policy issues are germane to other health plan conversions and more generally to the role of nonprofit organizations in health care.

\section{Origins of the Blue Cross and Blue Shield Plans}

Many of the health policy issues that arise in connection with the conversion to for-profit status of BCBS plans relate in some way to the original creation of the Blue Cross companies. As detailed in Blackstone and Fuhr (1998), most of the Blue Cross plans were initiated by the hospital industry in the 1920s and 1930s to provide hospital insurance at a time when hospitals experienced declining occupancy rates and escalating operating costs. Typically, these plans were established through state legislation as public-benefit organizations, and they were intended to serve as insurers of last resort. In enacting legislation to establish the Pennsylvania BC plan in 1937, Representative Herbert Cohen remarked:

The Legislature of Pennsylvania in approving this law was attempting to meet a severe need of providing citizens of Pennsylvania with hospital care at a cost within their means and also of providing hospitals with a source of financial support which would place them in a more stable financial position and therefore less dependent upon state and local tax funds. The Legislature therefore 
was attempting to fill a gap created by commercial insurance companies' underwriting policies which left the mass of Pennsylvania citizens unprotected from hospitalization expenses and hospital bills in many instances unpaid. ${ }^{2}$

The plans were exempted from state income taxes on premiums and in return were subject to various regulations and charged with a public service commitment. Blue Shield plans were created to provide insurance for physician services. The two insurance associations merged into the BCBS Association in 1982.3

\section{Nonprofit BCBS Plans and the Public Interest}

Because these plans were chartered as tax-exempt organizations for public benefit, state insurance commissioners are obligated to assess whether conversion to a public-stock company is in the public's interest. In addition, in the case in which conversion precedes the sale of a BCBS plan, the insurance commissioner must ascertain that the public receives fair value for the plan from the acquirer. ${ }^{4,5}$ In some instances, the proceeds of the sale are placed in a foundation; these funds are often used to meet the original objectives of the BCBS plans-to provide access to health care services for those in need. ${ }^{6}$

In reaching a judgment on whether conversion advances the public interest, state insurance commissioners are likely to take into account the potential effects of conversion on multiple stakeholders. For example, the insurance commissioner will want to know how conversion will affect insurance coverage for vulnerable populations and reimbursement to providers. This analysis of the effects of conversion will require an understanding of how, if at all, the behavior or conduct of the health plan might change as a result of the conversion and potential sale or merger. The insurance commissioner may consider at least six dimensions of health plan conduct. Each is discussed in the following subsections. Changes in the conduct of the health plan in any of these areas could influence access to health care, insurance coverage, the quality of the health care services provided, health status in the population, the financial health of providers, and the costs of health insurance to individuals and employers.

Products Offered and Markets Served. Most health plans offer several different health insurance products, and some of these products are tailored for particular subpopulations. Products may differ on several dimensions: the provider network, reimbursement for care 
provided by providers not in the network, co-insurance and copayment rates, services covered (i.e., benefit design), and maximum payments under the policy. In some states, nonprofit health plans are required to offer plans in which any person may enroll without regard for the individual's age, employment status, health status, or any other factor that might otherwise cause the individual to be denied health insurance. These plans are sometimes referred to as open enrollment plans. In deciding on the set of health insurance products to offer, health plans make implicit choices about whether to serve certain subpopulations. For example, not all health plans choose to offer a Medicaid or Medicare product; other noteworthy subpopulations include the small-business segment, the individual policy segment, and the Federal Employees Health Benefits Program (FEHBP).

Quality of Care. Health plans can influence the quality of health care services delivered to enrollees in several ways. Many of these levers require financial outlays by the health plan for patient and physician education, information systems, and program design and administration. For example, health plans may design and implement chronic disease management programs.

Quality of Service. Health plans have frequent interactions with enrollees about coverage issues, the status of particular claims, and the plan's provider network. The manner in which these inquiries are resolved may not directly affect quality of care but may indirectly affect access to care.

Pricing and Underwriting Practices. In some states, health insurance premiums for particular managed-care products are community rated, which means that the insurance regulator has eliminated the health plan's pricing decision and requires all plans serving a specific population to charge the same premium. In other states, premiums (and benefit design) for some products are subject to review by the insurance regulator. In yet other states, there is no regulatory oversight of health plan pricing policies. Depending on the regulatory regime of the state in which the health plan is operating, the health plan may be able to adjust premiums based on the risk factors of the group (or individual) to be insured. These are the firms' underwriting policies. 
Provider Networks and Reimbursement. In most states and for most products, health plans have a free hand in deciding which providers to include in their networks and in negotiating the level and the form of reimbursement for services delivered to enrollees. ${ }^{7}$ It is frequently noted anecdotally that some health plans reimburse at levels substantially above or below other health plans in the same market. Health plans may institute other policies that make it more or less difficult for the physician to be reimbursed for health care services. For example, some providers criticize utilization review and precertification as burdensome interventions that increase physicians' costs of delivering care and decrease patients' access to care.

Public and Community Health Efforts. Most health plans earmark some resources for outreach efforts intended to improve the health of community members regardless of enrollment in the health plan. These efforts include measures such as free screening for certain diseases and public health education.

\section{Necessary Conditions for Changes in Health Plan Conduct}

Whether the conversion or conversion/sale of a health plan is likely to alter the health plan's conduct on any of the above dimensions hinges on two conditions. First, depending on the regulatory environment and the nature of the market in which the health plan operates, the plan may or may not be able to change its conduct on some of these dimensions. For example, maybe all health plans operating in a particular state, regardless of their tax status, must reimburse hospitals according to the same mandated fee schedule. An alternative potential constraint on health plan conduct may be present in the level of market competition. Consultants to one health plan applying for conversion have argued that the market in which the health plan was operating was so competitive that it effectively limited the prices the health plan could charge and still attract enrollees. ${ }^{8}$

The second condition necessary for a conversion or a conversion/ sale to result in a change of conduct is that such change must be expected to increase the short- or long-term profitability of the health plan. Conceptually, a converting health plan could increase profitability in three ways. First, it could terminate the practice of crosssubsidizing premiums on unprofitable insurance products or subsidizing care delivery by certain providers. Eliminating a subsidy or cross-subsidy could increase profits but only at the expense of one 
of the stakeholders (i.e., some population of consumers or providers); thus, this type of change in conduct would amount to a value transfer from consumers and/or providers to shareholders.

The second mechanism through which a converting health plan may increase profits is through investment in new products and technologies. Two examples in this category come to mind. Some market observers and participants allege that nonprofit health plans have limited access to capital and therefore may be unable to make the necessary investments that would lead to new products or lower costs. Nonprofit health plans may also be subject to some organizational inertia and that, while they possess the necessary resources and capabilities, they do not feel compelled to innovate. This organizational inertia could be attributable to insulation from competitive pressure afforded by the state tax exemption on premiums. A change in conduct of this nature could lead to value creation because consumers would benefit from new products and reduced costs.

The third mechanism through which a converting health plan may increase profits is through improved efficiency resulting from enhanced accountability and governance structures. In nonprofit organizations, the residual claimants to the surplus created by an organization are unclear. Those who make decisions for the organization do not have a clear objective function; consequently it is difficult to identify suitable performance measures, to structure appropriate incentives, and to hold decision makers accountable. Reducing inefficiency through improved accountability and governance structures is a value-creating activity because it results in services being delivered at the lowest cost to society overall.

Recall that the insurance commissioner must determine whether a conversion is likely to advance the public interest. If the expected changes in health plan behavior do not have the potential to create additional value and are simply a transfer from consumers and providers to prospective shareholders, it would seem difficult to argue that the conversion is in the public interest. On the other hand, if the expected changes in health plan behavior are likely to result in new and better products, conversion may indeed advance public welfare. In all likelihood, a health plan conversion will have the potential for both value creation and value transfer. In these cases, the insurance commissioner must, in essence, make a judgment that involves trade-offs among different stakeholders. 


\section{Other Considerations Beyond Changes in Health Plan Conduct}

The simple alternatives of approving or denying the conversion petition are more complicated than they might seem at first glance. The consequences of approving the conversion are not simply the anticipated costs and benefits of changes in health plan conduct; one must also consider the opportunities afforded by an endowed foundation charged with the mission of serving the public interest. The consequences of denying the conversion are not simply the preservation of the status quo. One must consider the factors that prompted the conversion petition in the first place and what they signal about the evolution of the local health care market and the viability of the health plan petitioning to convert.

To assess whether a foundation could more efficiently execute the public-service mission of a nonprofit health plan, it is instructive first to evaluate the extent to which the petitioning health plan is currently executing this mission and to approximate the resources it requires (both financial and organizational) to do so. Only then can one determine whether a foundation can accomplish the same task at a lower cost or implement an expanded mission with the funds available from the conversion.

Oversight of a nonprofit health plan's execution of its mission is not typically considered to be in the purview of state insurance regulators and is largely delegated to board members. Some question surrounds whether these nonprofit health plans are completely fulfilling their missions as public-benefit organizations. In written testimony submitted to the Maryland Insurance Administration in March 2002, William Jews, the chief executive officer (CEO) of the CareFirst Blue Cross Blue Shield Company explains when and why the Blue Cross Blue Shield of Maryland (BCBSMD) plan stopped filling the role of insurer of last resort:

As with other Blues Plans being formed at about the same time, the [Blue Cross Blue Shield of Maryland plan] was conceived with the goal of providing affordable health care insurance using "community rating" principles. This worked effectively at a time when few, if any, commercial carriers were offering health coverage. In the 1960s, commercial insurance carriers began entering the health insurance market in earnest and introduced the concept of "experience rating." As commercial carriers focused on providing coverage at lower premiums to the healthiest individuals and groups, Blues Plans like BCBSMD continued to extend coverage to all comers, including high risk through its community rating 
mechanism. As a result, many Blue Plans became known as "insurers of last resort" in their service areas....

That role of insurer of last resort changed in the 1960s when the federal government-in essence-assumed the mantle of insurer of last resort by establishing the Medicare and Medicaid programs to guarantee health covered to the aged and disabled and to provide coverage to the poor. From that point forward, Blues Plans began to compete with commercial insurance carriers and the long-standing expectation that "Blues" would act as the insurer of last resort was greatly minimized. In addition, the continued use by our competitors of experience rating, which gave them an unfair advantage, forced most Blue Plans to abandon community rating in order to survive.

Jews contends that the creation of public insurance programs by the federal government relieved the Blues plans of fulfilling their role as insurers of last resort. If the public-service mission of BCBS plans is limited to the narrow interpretation of providing affordable health insurance using community rating, and if this mission has been abandoned by BCBS plans seeking to convert, then the insurance commissioner's decision about whether to approve a conversion petition is somewhat simplified. Under the current organization and governance structure, the nonprofit plan is receiving a tax exemption while operating in a manner closely resembling that of a for-profit health plan; the foregone tax receipts and the alternative uses of the plan's assets are the opportunity costs of disallowing the conversion and requiring the health plan to continue under the status quo.

The insurance commissioner may decide, however, that the public interest would be better served by going beyond denial of the petition and instituting reform of the health plan governance structures and accountability systems to ensure that it pursues its original mission. Whether or not this approach is the best course of action hinges on two additional analyses: (1) an assessment of whether the mission will be executed more efficiently by a suitably reformed nonprofit health plan or a newly created foundation, and (2) whether either institution is viable in the long run.

In his statements above, Jews asserts that the BCBSMD plan was compelled to abandon its original mission so it could survive competition from commercial insurance carriers. These views are echoed in a recent account of the conversion of the Blue Cross and Blue Shield plan of New York. ${ }^{9}$ James Robinson recounts how state 
regulators destroyed the delicate balancing act of cross-subsidization achieved by Empire BCBS when the regulators allowed commercial insurers to enter the market and attract healthy low-cost enrollees with lower premiums. These actions precipitated an adverse selection spiral that left Empire with the sickest enrollees and the highest costs. In general, the long-term financial viability of an efficient nonprofit is unknown. Research on the regulatory structures that might support a nonprofit health plan and the social efficiency of such regimes is also limited.

The foregoing analysis suggests a framework for guiding research and decision making on health plan conversions (see figure 5.3). Prior to evaluating the potential changes in health plan conduct and the effects of these changes on public welfare, the insurance commissioner might first want to consider whether:

1. The public interest mission of the nonprofit can be achieved more efficiently through a foundation or a health insurance plan.

2. Any organization can faithfully execute this mission and remain financially viable.

After making these assessments, the insurance commissioner must then weigh the costs and benefits to different constituencies of likely changes in health plan conduct.

\section{Case Study}

In the previous section of this paper, I described, in a generic sense, some of the health policy issues that arise when a nonprofit health plan petitions a state insurance regulator to convert to a public-stock company (potentially to be acquired by another company). In this section, I present some case study research conducted when the CareFirst Blue Cross and Blue Shield Company (with licenses in Delaware, Maryland, and Washington, D.C.) petitioned to convert to a public-stock company, and to be acquired by Wellpoint Health Networks, Inc. I provide a brief description of the CareFirst organization and the events leading up to the conversion petition. Then I summarize the main arguments both for and against the conversion as they have been presented in oral and written testimony, in publicly available reports, and in the public press. Next, I present the results of the analyses of market structure, economies of scale, and 


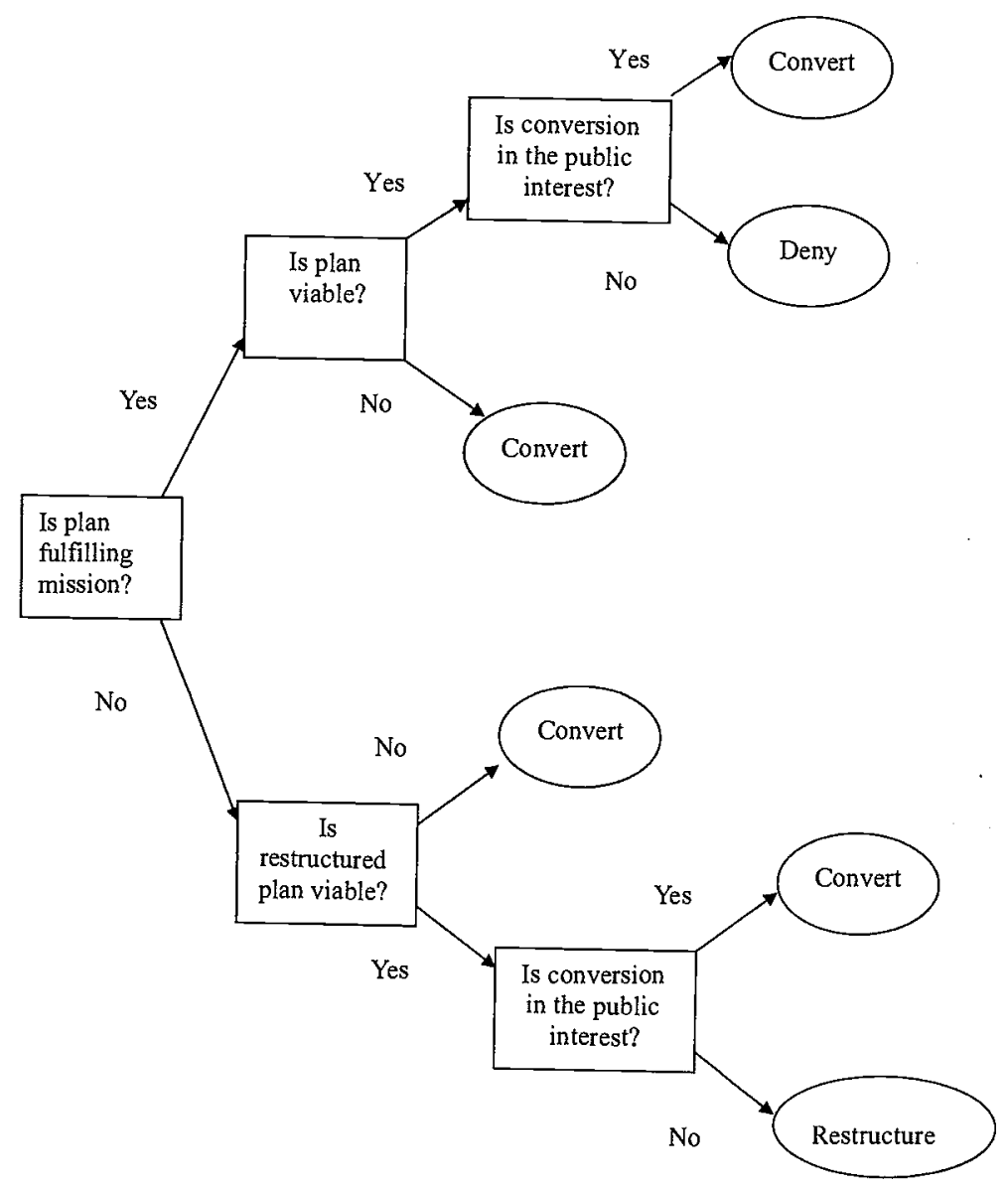

Figure 5.3

Decision calculus for conversions

quality of care. Finally, I report on the outcome of the petition and the research challenges remaining.

\section{Background on CareFirst}

CareFirst, Inc. is a holding company with BCBS licenses for Delaware, the District of Columbia, and Maryland. The company was formed in 1998 with the merger of BCBS of Maryland and BCBS of the National Capital Area (District of Columbia). In 2000, BCBS of Delaware became part of CareFirst. 
CareFirst is overseen by a central board of directors; William Jews is the CEO of CareFirst and CEO of each of the three subsidiaries that make up CareFirst: Group Hospitalization and Medical Services Inc.GHMSI (the D.C. Blues), CareFirst of Maryland (the Maryland Blues), and BCBSD (the Delaware Blues). The CareFirst corporation offers a wide variety of insurance products in these three jurisdictions.

In November 2001, CareFirst entered into a merger agreement with Wellpoint Health Networks, Inc. of California. To consummate this merger agreement, CareFirst needed to convert to a for-profit publicstock company. The insurance commissioners in all three jurisdictions in which CareFirst operates needed to approve the conversion petition; however, Maryland was the first jurisdiction to initiate formal proceedings to evaluate the merits of conversion. As part of the proceedings in Maryland and in the District of Columbia, public hearings and discovery were conducted to generate information to inform the public-interest determination. Valuation studies of CareFirst were also initiated.

\section{Summary of Arguments for and Against Conversion}

The CareFirst management team and its consultants advanced three primary reasons in support of the conversion petition. First, they cited an inability to access sufficient capital to fund investments that would enhance efficiency, improve customer service, and facilitate the development of new and better products. In the consultant's report and in CareFirst's strategic plan, however, it appeared that the need for capital was largely driven by plans for acquiring other health plans. The need to achieve economies of scale was cited as the primary reason for this acquisition strategy. Second, without these improvements (and larger scale), they contended that CareFirst's long-run viability was uncertain. Approving the conversion would therefore "help to secure the long-term future of the 'Blue' brand in local markets." 10 Third, approving the conversion and merger with Wellpoint would benefit the public because it would result in additional tax receipts (estimated to be $\$ 20$ million annually) and the creation of a foundation with an endowment of $\$ 1.3$ billion that would be apportioned to the three jurisdictions.

Those opposing the conversion cited various concerns, many of which related to the future conduct of a for-profit BCBS plan. Concerns about access to care stemmed from the expectation that after conversion, CareFirst would discontinue offering insurance products that 
served vulnerable populations and that were relatively unprofitable. Some people feared that CareFirst would raise premiums, tighten underwriting practices (abandon guaranteed issue), and narrow the coverage of the insurance policies it continued to offer. Another policy concern related to the potential for skimping on quality. Some providers were not supportive of the conversion petition because they feared reductions in payment rates, increased administrative burden, and a more adversarial relationship. Both providers and consumers feared the loss of a local institution led by members of the community with the long-run interests of the community in mind. Two objections to the conversion were unrelated to anticipated changes in health plan conduct. Some people felt that Wellpoint's offer of $\$ 1.3$ billion to acquire CareFirst was less than the fair value of CareFirst as an ongoing concern. ${ }^{11}$ Finally, many consumers were outraged about the bonuses CareFirst executives were scheduled to receive if the deal went through.

\section{Economic Analyses}

Market Structure. CareFirst executives and consultants have suggested in their filings that the markets in which the CareFirst plans operate are so competitive that they constrain their ability to raise premiums or lower quality without losing enrollees to other local health plans. They imply that CareFirst, if it were allowed to convert to forprofit status, would not take such actions (raising premiums or lowering quality) because the loss of enrollment would decrease profits. Traditionally, economists have used market-share summary measures as proxies for market competitiveness. The belief is that greater concentration of market share among a smaller number of firms is likely to result in higher prices.

Computing market shares in practice requires definition of the market and detailed data for each firm. Market definitions can have large effects on both measures of concentration and market shares for individual firms. In this section, I examine the extent of market concentration in the District of Columbia (D.C.) using data on HMO and managed-care enrollment. ${ }^{12}$ I am able to obtain relatively complete enrollment data for health plans licensed to do business in D.C.; these detailed data facilitate analyses of market share by consumer segment and product type. However, CareFirst also sells policies in Maryland, Virginia, and Delaware. A complete analysis of the market power possessed by CareFirst would require comparable analyses in these other geographic markets. 
D.C. Health Plan Enrollment. Table 5.1 reports the health plan enrollment and market share for each health plan licensed to sell health insurance policies in D.C. for the years 2000 and $2001 .^{13}$ In 2001, there were a total of fourteen health plans, most of which fall into one of three categories. Four national for-profit companies (Aetna U.S. Healthcare, AMERIGROUP, Cigna, and United Healthcare) did a small amount of business in D.C. (combined market share of roughly 10.1 percent). Three other health plans (George Washington. University Health Plan, Optimum Choice, and MD-Individual Practice Association) could be characterized as relatively small regional plans because they operated in a small number of adjacent states. In 2001, these regional plans accounted for 15.6 percent of the market. Four health plans (Health Right Inc., DC Chartered Health Plan, Advantage Health Plan, and Capital Community Health Plan) offered products only in D.C.; together these plans accounted for 3.5 percent of the market.

\section{Table 5.1}

Health plan enrollment in the District of Columbia, 2000-2001

\begin{tabular}{|c|c|c|c|c|}
\hline & \multicolumn{2}{|l|}{2001} & \multicolumn{2}{|l|}{2000} \\
\hline & Enrollment & Share & Enrollment & Share \\
\hline Advantage Healthplan & 3,194 & 0.00 & 3,471 & 0.00 \\
\hline $\begin{array}{l}\text { Aetna U.S. Healthcare } \\
\text { (a Maryland corporation) }\end{array}$ & 177,820 & 0.09 & 179,469 & 0.10 \\
\hline AMERIGROUP Maryland, Inc. & 12,876 & 0.01 & 12,640 & 0.01 \\
\hline Capital Community Health Plan & 28,851 & 0.02 & 25,955 & 0.01 \\
\hline CareFirst BlueChoice Inc. & 46,534 & 0.02 & 46,525 & 0.03 \\
\hline Cigna Healthcare Mid-Atlantic, Inc. & 1,655 & 0.00 & 2,146 & 0.00 \\
\hline DC Chartered Health Plan, Inc. & 26,877 & 0.01 & 27,687 & 0.01 \\
\hline GHMSI & 924,798 & 0.48 & 879,338 & 0.47 \\
\hline GW University Health Plan & 82,854 & 0.04 & 100,980 & 0.05 \\
\hline Health Right, Inc. & 9,168 & 0.00 & 4,838 & 0.00 \\
\hline Kaiser of the Mid-Atlantic & 376,877 & 0.20 & 389,349 & 0.21 \\
\hline MD-IPA, Inc. & 171,207 & 0.09 & 130,064 & 0.07 \\
\hline Optimum Choice & 44,233 & 0.02 & 25,612 & 0.01 \\
\hline Prudential Health Care Plan, Inc. & 0 & 0.00 & 23,918 & 0.01 \\
\hline $\begin{array}{l}\text { United Healthcare of the } \\
\text { Mid-Atlantic, Inc. }\end{array}$ & 1,279 & 0.00 & 1,648 & 0.00 \\
\hline Total & $1,908,223$ & & $1,853,640$ & \\
\hline Herfindahl & & 0.29 & & 0.29 \\
\hline
\end{tabular}


Omitted from this categorization are two CareFirst plans and the Kaiser plan. CareFirst operates two health plans in D.C.: CareFirst BlueChoice (hereafter BlueChoice) and Group Hospitalization and Medical Services, Inc. (GHMSI). Together these plans represent 50.9 percent of the market; however, GHMSI, with a 48.5 percent share, dominates in this market. Kaiser Foundation Health Plan has the second largest share of the D.C. market (19.8 percent) and does not fit neatly into any of the above three categories. It is affiliated with the only national nonprofit health plan in the United States.

Total health plan enrollment in D.C. grew 2.9 percent from 2000 to 2001. All national for-profit plans (with the exception of AMERIGROUP, which gained 200 enrollees) lost market share over this time period. Prudential Health Care operated a plan in 2000, but it terminated this local plan in 2001 following its acquisition by Aetna Health Plans. Two regional plans experienced substantial increases in enrollment (MD-IPA grew by 41,000; Optimum Choice grew by 18,600); the third regional health plan, George Washington University Health Plan, lost roughly 18,000 enrollees. GHMSI experienced the largest absolute enrollment gains during this period, adding more than 45,000 enrollees.

D.C. Enrollment by Consumer Segment. As shown in table 5.2, health plans operating in D.C. sell policies to several different consumer segments; however, enrollment in two of these segments (the commercial group and Federal Employee Health Benefits Program [FEHBP] segments) constitutes 91.5 percent of all health insurance policies sold in D.C. The largest market segment is the commercial group market, which accounts for 47 percent of all health insurance policies; GHMSI and BlueChoice together hold a 51 percent share of this segment. Commercial group products are typically sold to employers (large and small), who in turn offer these health plans as a benefit to their employees at some fraction of the per-enrollee cost to the employer.

The second largest segment is FEHBP; the FEHBP segment is very similar to the commercial group segment because the federal government essentially acts as a large employer. One difference between these two segments is that any health plan meeting a minimum set of criteria may participate in FEHBP (i.e., offer a health plan to federal employees); private-sector employers typically contract selectively with a very small number of health plans. The FEHBP market segment is nearly as large as the commercial group segment (44 percent of 


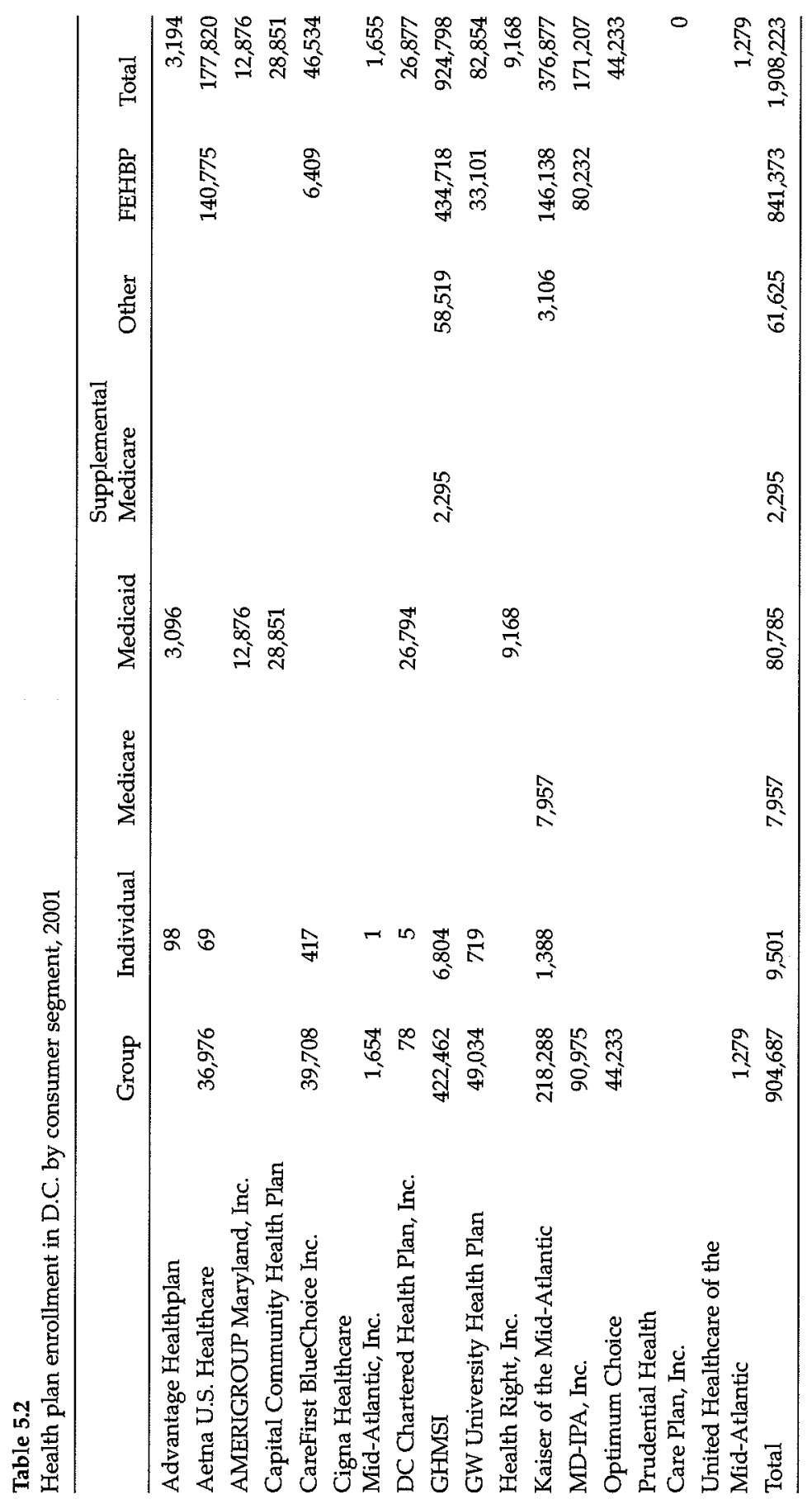


policies). Six health plans in D.C. offer a policy designed specifically for federal employees, but GHMSI alone holds 51.7 percent of the market.

Health Plan Enrollment by Product Type. Managed-care companies typically offer several different health insurance products in the commercial group segment of the market. These products vary in terms of the health care providers that members may receive care from and who bears the risk that total premiums may not equal total expenses during the time the policy is in effect. At one end of the spectrum is the HMO product; for HMO policies, the managed-care company bears all the risk and members are restricted to a prespecified provider network. ${ }^{14}$ At the other end of the spectrum is the indemnity product; for indemnity policies (which are rare today), the policyholder and the managedcare company jointly share risk up to some maximum benefit. Policyholders may receive care from any licensed provider.

Between these two extremes are preferred-provider-organization (PPO) products and point-of-service (POS) products. In both PPO and POS plans, the sponsoring managed-care company identifies a preferred list of providers. In the case of a POS, this preferred list of providers is usually the provider network for an HMO product; in the case of a PPO, the preferred providers have entered into contracts with the managed-care organization in which they have discounted the fees they charge. When a member of a PPO or a POS seeks care from a provider not included on the preferred provider list, the member is responsible for a co-insurance payment-a fixed percentage of the total amount that the nonpreferred provider charges the health plan for his or her services. When a member of a POS plan receives care from a preferred provider, there is typically no co-insurance payment. When a member of a PPO receives care from a preferred provider, there is typically a smaller co-insurance payment compared to the times when services are obtained from a nonpreferred provider. Because of differences in their provider networks and their benefit design, PPO products are imperfect substitutes for HMO products. Table 5.3 provides a brief description of different health insurance products.

Table 5.4 presents statistics on total health plan enrollment by product type in 2001 for health plans operating in D.C. ${ }^{15}$ Approximately 71 percent of all health insurance products marketed by these health plans in the D.C.-Maryland-Virginia region are HMO products. The next largest category is the PPO product, which represents 21 percent of all health insurance products sold in this region by health plans that 
Table 5.3

Descriptions of health insurance products as defined by InterStudy

Health insurance

product

Direct pay enrollment

FEHBP

Commercial group

Public programs

Point of service (POS)

Open-ended HMO

Preferred provider organization (PPO)

Managed fee for service (FFS)

Self-insured

Supplemental Medicare

Other non-HMO plans
Description

Enrollees are individuals who are not members of a contracting group (i.e., they are enrolled under an individual coverage option).

Enrollees are federal employees and participate in the Federal Employees Health Benefits Program.

Includes individuals enrolled through employer-sponsored group HMO policies, as well as conversion members (persons who are no longer members of an employer group but under COBRA regulations are still eligible for $\mathrm{HMO}$ services at a group rate).

Recipients of Medicaid and Medicare who are enrolled in an HMO.

Enrollees have access to and financial incentives to use a managed-care provider network, often the HMO's provider panel, but in contrast to the open-panel HMO, POS enrollees are not prepaid enrollees of the HMO (they pay indemnity. premiums).

Enrollees are prepaid members of the $\mathrm{HMO}$ and may receive nonemergency services from providers outside the HMO's network. A substantial deductible, copayment, or need for coinsurance is usually required for use of nonpanel providers.

A fee-for-service product where beneficiaries receive care from a selected panel of providers. Providers agree to a discounted fee schedule when contracting with the PPO. PPOs offer a wide variety of benefit plans; some include the option of using nonpanel providers if beneficiaries pay outof-pocket costs.

The insurer pays the cost of covered services after services have been received and according to an agreed-on fee schedule. Various managed-care tools such as precertification, second surgical opinion, and utilization review are used.

The HMO providers deliver health services to an individual, but rather than being prepaid enrollees or premium paying beneficiaries, services received are paid for directly by the enrollee's employer.

A Medicare wraparound plan that covers some co-payments, deductibles, and services not covered under traditional Medicare. Beneficiaries are given financial incentives to use HMO providers but are not restricted to the HMO's panel.

This category primarily includes enrollees in flexcare plans, self-insured Medicare plans, managed indemnity, indemnity, exclusive provider organizations (EPOs), and out-of-area plans. 
Table 5.4

Total regional health plan enrollment in 2001 , by product type ${ }^{a}$

\begin{tabular}{|c|c|c|c|c|c|}
\hline & $\mathrm{HMO}$ & $\mathrm{PPO}$ & POS & Indemnity & Total \\
\hline $\begin{array}{l}\text { Kaiser Foundation } \\
\text { Health Plan }\end{array}$ & 501,088 & & 14,860 & & 515,948 \\
\hline $\begin{array}{l}\text { Prudential Health } \\
\text { Care Plan }\end{array}$ & 0 & & & & 0 \\
\hline Health Right, Inc. & 9,168 & & & & 9,168 \\
\hline Optimum Choice, Inc. & 392,153 & & & & 392,153 \\
\hline $\begin{array}{l}\text { MD-Individual } \\
\text { Practice Assoc, Inc. }\end{array}$ & 122,860 & & & & 122,860 \\
\hline $\begin{array}{l}\text { DC Chartered } \\
\text { Health Plan }\end{array}$ & 26,877 & & & & 26,877 \\
\hline United Healthcare & 180,478 & & & & 180,478 \\
\hline $\begin{array}{l}\text { Capital Community } \\
\text { Health Plan }\end{array}$ & 28,085 & & & & 28,085 \\
\hline $\begin{array}{l}\text { Amerigroup } \\
\text { Maryland, Inc. }\end{array}$ & 131,430 & & & & 131,430 \\
\hline $\begin{array}{l}\text { Aetna U.S. } \\
\text { Healthcare, Inc. }\end{array}$ & 369,004 & & 36,396 & & 405,400 \\
\hline Cigna Healthcare & 32,589 & & 4,485 & & 37,074 \\
\hline $\begin{array}{l}\text { GW University } \\
\text { Health Plan }\end{array}$ & 59,545 & & 3,882 & & 63,427 \\
\hline CareFirst BlueChoice & 123,372 & & 45,572 & & 168,944 \\
\hline GHMSI & & 589,251 & 85,058 & 38,232 & 712,541 \\
\hline $\begin{array}{l}\text { Advantage } \\
\text { Healthplan, Inc. }\end{array}$ & 3,194 & & & & 3,194 \\
\hline Total & $1,979,843$ & 589,251 & 190,253 & 38,232 & $2,797,579$ \\
\hline
\end{tabular}

aTotal health plan enrollment excluding FEHBP enrollment.

participate in the D.C. market. Note that all health plans offer an HMO product except for GHMSI, and that only GHMSI offers a PPO product or an indemnity product. GHMSI does not compete with any other managed-care firm in these two product markets and has the largest market share (approximately 45 percent) in the POS product market. CareFirst BlueChoice membership represents an additional 24 percent market share in the POS product market.

Market Concentration. Economists frequently employ the Herfindahl measure to quantify the extent to which market share is concentrated in a small number of firms. The Herfindahl concentration measure is computed as the sum of squared market shares for all firms in the mar- 
ket. If there is only one firm in the market (i.e., a monopoly), the Herfindahl statistic equals 1.0. If there are two firms of equal size in the market, the Herfindahl statistic equals 0.5. Economists are interested in market concentration because they believe it is related to a firm's bargaining power with suppliers and the ability of individual firms to affect the price at which the market clears.

The Herfindahl statistic for the entire D.C. health insurance market is 0.29 , which is roughly equivalent to having three to four firms of equal size in the market. In some more narrowly defined market segments, the Herfindahl statistics are substantially higher. For example, the Herfindahl statistic in the individual market (policies sold to individual consumers and not through a group purchaser) is 0.54 ; GHMSI's share of this market is 72 percent. The Herfindahl statistic in the FEHBP segment is 0.34 , and GHMSI's market share is 52 percent. In D.C., GHMSI is the only managed-care firm in the PPO and indemnity market segments (Herfindahl $=1.0$ ). Table 5.5 presents the Herfindahl statistic and GHMSI's market share for each market segment in which it participates.

Market Dynamics. Point-in-time statistics on enrollment and market share provide an incomplete picture of the competitive nature of a market. One might like to know which products, if any, have gained in

\section{Table 5.5}

Herfindahl statistics and GHMSI market share for market segments, 2001

\begin{tabular}{lll}
\hline Market segment & Herfindahl & GHMSI market share \\
\hline Commercial Group & 0.30 & 0.47 \\
FEHBP & 0.34 & 0.52 \\
Individual & 0.54 & 0.72 \\
Medicare Supplemental & 1.00 & 1.00 \\
PPO & 1.00 & 1.00 \\
POS $^{\text {a }}$ & 0.30 & 0.45 \\
Indemnity & 1.00 & 1.00 \\
\hline
\end{tabular}

aBecause enrollment by product type is reported only at the health plan level for the entire D. C.-Maryland-Virginia market area, the Herfindal and GHMSI market share statistics are difficult to interpret. It is possible that managed-care companies offer POS products in Maryland and Virginia but not in the District of Columbia. This situation would cause the Herfindahl and GHMSI market share statistics in Table 5.4 to overstate the true measures. Perhaps in the District, GHMSI is the only health plan offering a POS product; in that case, the reported Herfindahl and GHMSI market share would underestimate the true measures. 
popularity in recent years. Comparable historical data from health plan filings with the D.C. insurance commission were not available to construct a longtitudinal version of table 5.5. Enrollment by product type was available, however, from the InterStudy database for the years 1999 and 2001 for any health plan offering an HMO. ${ }^{16}$

Table 5.6 reports changes in the sum total of enrollment by product type for health plans that offer an HMO and whose primary service area is the District of Columbia, Maryland, or Virginia. These enrollment changes are also broken down by plan ownership type: national forprofit, Virginia Blue Cross Blue Shield, independent (includes for-profit and nonprofit), and CareFirst. A list of health plans in each ownership category is included in table 5.7.

The largest decreases in total enrollment marketwide occurred in the commercial group HMO product line and in the open-panel HMO product line. The largest increases occurred in PPO enrollment and enrollment in other non-HMO products. Data in table 5.6 suggest that the national for-profit firms decreased enrollment in commercial group HMO products and made up for about 83 percent of this HMO enrollment decrease with enrollment increases in PPO and other non-HMO

Table 5.6

Changes in enrollment by product type in the D.C.-Maryland-Virginia region, 1999-2001

\begin{tabular}{|c|c|c|c|c|c|c|}
\hline & \multirow{2}{*}{$\begin{array}{l}2001 \\
\text { Total } \\
\text { enrollment }\end{array}$} & \multicolumn{5}{|c|}{ Enrollment change: 1999-2001 } \\
\hline & & $\begin{array}{l}\text { National } \\
\text { for-profit }\end{array}$ & $\begin{array}{l}\text { VA- } \\
\text { BCBS }\end{array}$ & Independent & CareFirst & Total \\
\hline \multicolumn{7}{|l|}{ Commercial } \\
\hline $\mathrm{HMO}$ & $1,759,586$ & $-419,530$ & $-28,726$ & $-58,556$ & 34,899 & $-471,913$ \\
\hline PPO & 645,149 & 101,435 & 0 & $-1,011$ & 355,443 & 455,867 \\
\hline FEHBP & 463,346 & $-13,142$ & 1,746 & 15,714 & $-7,055$ & $-2,737$ \\
\hline Public & 455,393 & 45,075 & 27,128 & $-3,425$ & $-125,900$ & $-57,122$ \\
\hline Self & 434,079 & $-137,959$ & 0 & $-14,897$ & 202,671 & 49,815 \\
\hline \multicolumn{7}{|l|}{ Open-Panel } \\
\hline HMO & 382,013 & $-111,823$ & $-10,017$ & $-3,728$ & $-84,608$ & $-210,176$ \\
\hline $\begin{array}{l}\text { Other } \\
\text { non-HMO }\end{array}$ & 275,474 & 245,378 & 0 & 26,306 & 0 & 271,684 \\
\hline POS & 146,220 & $-45,365$ & 0 & 0 & 0 & $-45,365$ \\
\hline Direct & 62,587 & $-9,927$ & $-3,224$ & $-2,445$ & -750 & $-16,346$ \\
\hline FFS & 0 & 0 & 0 & 0 & 0 & 0 \\
\hline Supplemental & 0 & 0 & 0 & 0 & 0 & 0 \\
\hline $\begin{array}{l}\text { Total } \\
\text { managed care }\end{array}$ & $4,626,062$ & $-345,887$ & $-13,093$ & $-42,759$ & 374,700 & $-27,039$ \\
\hline
\end{tabular}


Table 5.7

InterStudy health plans by ownership type in the D.C.-Maryland-Virginia market, 2001

\begin{tabular}{|c|c|c|c|}
\hline $\begin{array}{l}\text { National for-profit } \\
\text { plans }\end{array}$ & $\begin{array}{l}\text { Virginia: Blue } \\
\text { Cross Blue Shield }\end{array}$ & $\begin{array}{l}\text { Independent } \\
\text { plans }\end{array}$ & CareFirst plans \\
\hline $\begin{array}{l}\text { United Healthcare of } \\
\text { Mid-Atlantic }\end{array}$ & Healthkeepers & $\begin{array}{l}\text { Kaiser of the } \\
\text { Mid-Atlantic }\end{array}$ & $\begin{array}{l}\text { FreeState } \\
\text { HealthPlan }\end{array}$ \\
\hline $\begin{array}{l}\text { Aetna U.S. Healthcare } \\
\text { (Maryland) }\end{array}$ & $\begin{array}{l}\text { Peninsula } \\
\text { Health Care }\end{array}$ & $\begin{array}{l}\text { GW University } \\
\text { Health Plan }\end{array}$ & $\begin{array}{l}\text { Delmarva } \\
\text { Health Plan }\end{array}$ \\
\hline $\begin{array}{l}\text { Prudential/Aetna } \\
\text { (Virginia) }\end{array}$ & $\begin{array}{l}\text { Priority } \\
\text { Health Care }\end{array}$ & M.D.-IPA & $\begin{array}{l}\text { CareFirst } \\
\text { BlueChoice }\end{array}$ \\
\hline $\begin{array}{l}\text { CIGNA Healthcare } \\
\text { of VA }\end{array}$ & & $\begin{array}{l}\text { OPTIMA } \\
\text { Health Plan }\end{array}$ & PHN-HMO \\
\hline $\begin{array}{l}\text { Southern Health } \\
\text { Services }\end{array}$ & & $\begin{array}{l}\text { QualChoice } \\
\text { of Virginia }\end{array}$ & \\
\hline $\begin{array}{l}\text { CIGNA Healthcare of } \\
\text { Mid-Atlantic }\end{array}$ & & $\begin{array}{l}\text { Optimum } \\
\text { Choice }\end{array}$ & \\
\hline $\begin{array}{l}\text { Prudential/Aetna } \\
\text { (Maryland) }\end{array}$ & & $\begin{array}{l}\text { Carilion } \\
\text { Health Plans }\end{array}$ & \\
\hline $\begin{array}{l}\text { United Healthcare } \\
\text { of VA }\end{array}$ & & $\begin{array}{l}\text { D.C. Chartered } \\
\text { Health Plans }\end{array}$ & \\
\hline \multirow[t]{3}{*}{$\begin{array}{l}\text { AMERIGROUP } \\
\text { (Maryland) }\end{array}$} & & $\begin{array}{l}\text { Piedmont } \\
\text { Community } \\
\text { HealthCare }\end{array}$ & \\
\hline & & $\begin{array}{l}\text { Advantage } \\
\text { Healthplan }\end{array}$ & \\
\hline & & $\begin{array}{l}\text { Capital } \\
\text { Community } \\
\text { Health Plan }\end{array}$ & \\
\hline
\end{tabular}

products. Unlike other health plans in the D.C.-Maryland-Virginia market, CareFirst plans increased their commercial group HMO enrollment but decreased enrollment in all other HMO products. These decreases were more than offset, however, by large increases in PPO enrollment and enrollment in self-insured products.

Comparable nationwide enrollment changes between 1999 and 2001 are presented in table 5.8. Similarities between trends in the D.C.-Maryland-Virginia markets and nationwide include a substantial increase in PPO enrollment, a substantial decrease in commercial group and POS enrollment, and a decrease in nongroup direct enrollment products. In contrast to nationwide enrollment trends, total managed-care enrollment, FEHBP enrollment, and public program enrollment decreased in plans offering an HMO in the D.C.-MarylandVirginia market, while they increased nationwide. Overall, however, it 
Table 5.8

Enrollment changes nationwide, 1999-2001

\begin{tabular}{|c|c|c|c|c|c|c|}
\hline & \multirow{2}{*}{$\begin{array}{l}2001 \\
\text { Total } \\
\text { enrollment } \\
\text { (thousands) }\end{array}$} & \multicolumn{5}{|c|}{ Enrollment change: 1999-2001 (thousands) } \\
\hline & & $\begin{array}{l}\text { National } \\
\text { managed } \\
\text { care }\end{array}$ & $\begin{array}{l}\text { Not-for } \\
\text { profit } \\
\text { BCBS }\end{array}$ & $\begin{array}{l}\text { For } \\
\text { profit } \\
\text { BCBS }\end{array}$ & Independent & Total \\
\hline $\begin{array}{l}\text { Commercial } \\
\text { Group HMO }\end{array}$ & 46,722 & $-4,429$ & 73 & 1,384 & $-1,172$ & $-4,144$ \\
\hline PPO & 36,324 & 4,376 & 817 & 6,917 & 2,289 & 14,399 \\
\hline FEHBP & 2,362 & -114 & 128 & 20 & 63 & 97 \\
\hline $\begin{array}{l}\text { Public } \\
\text { programs }\end{array}$ & 17,746 & -581 & 1,295 & $-1,002$ & 1,174 & 886 \\
\hline Self-insured & 6,759 & -98 & 749 & 697 & -280 & 1,068 \\
\hline $\begin{array}{l}\text { Open-ended } \\
\text { HMO }\end{array}$ & 8,563 & -164 & 14 & 257 & -381 & -273 \\
\hline $\begin{array}{l}\text { Other } \\
\text { non-HMO }\end{array}$ & 6,879 & 3,108 & 575 & 115 & 427 & 4,225 \\
\hline POS & 6,637 & -895 & -423 & $-1,640$ & 111 & $-2,848$ \\
\hline Direct pay & 1,562 & -256 & 114 & -213 & -121 & -475 \\
\hline Managed FFS & 2,334 & -79 & -107 & 900 & 309 & 1,023 \\
\hline $\begin{array}{l}\text { Supplemental } \\
\text { Medicare }\end{array}$ & 1,040 & -21 & 305 & 445 & 73 & 803 \\
\hline $\begin{array}{l}\text { Total } \\
\text { managed care }\end{array}$ & 137,998 & 858 & 3,631 & 7,917 & 2,619 & 15,025 \\
\hline
\end{tabular}

seems that enrollment trends in the D.C.-Maryland-Virginia market area are similar to enrollment trends nationwide.

In summary, the market-share analysis indicates that the CareFirst plan, GHMSI, dominates the D.C. health insurance market. GHMSI has a large market share in the largest consumer segments. Furthermore, the markets in which GHMSI dominates are also concentrated. This combination suggests that GHMSI possesses market power in D.C. The next largest plan in the D.C. market is the Kaiser plan; note that the national for-profit health plans that CareFirst managers perceive as their primary competitors hold relatively small market shares in D.C. Because the market structure analyses were limited to the D.C. market, it is not possible to speculate whether other CareFirst plans possess similar favorable positions in the Maryland and Delaware markets.

National and local enrollment trends suggest a decline in traditional HMO and POS products and increases in PPO and other non-HMO products. CareFirst plans are at the forefront of this trend in the PPO 
market, but they lag behind the national for-profit firms in the market for other non-HMO products.

Economies of Scale. CareFirst executives and consultants have argued that the firm's acquisition by Wellpoint will lower CareFirst costs because of economies of scale. Strictly speaking, economies of scale are present when average unit costs fall with increased output. Average unit costs may decrease over some range of output for two reasons. First, large capital investments represent fixed costs that lead naturally to declining average costs up to some capacity constraint. Second, marginal costs may fall over some range of output because of learning curves, specialization, or volume discounts from suppliers.

In the health insurance market, economies of scale are present when the average total cost of insuring an individual is lower with high levels of total health plan enrollment than with low levels of total plan enrollment. Several intuitive reasons can explain why economies of scale might be present in managed-care operations. First, insurance is largely an information business and requires substantial capital investment in computers and software to manage that information. As long as the information systems are not at some capacity constraint, the information technology (IT) costs of processing information for an additional enrollee is essentially zero; hence, health plans can lower average costs by spreading these fixed costs of capital investment over a larger enrollment base. In a similar vein, health plans with a larger enrollment base may be able to support a larger Research and Development $(R \& D)$ group and have more opportunities for lower cost experimentation with new products and processes. Fixed costs are also associated with negotiating contracts with health care providers and purchasers.

Second, greater health plan enrollment may increase the bargaining power that the health plan can exercise in its negotiations over reimbursements with health care providers (e.g., doctors, hospitals, and pharmaceutical companies). The extent to which increased enrollment translates into greater bargaining power and lower medical-care costs (and hence lower average total costs) depends on local market characteristics. In markets where providers are themselves consolidated into large bargaining units or in which the demand for certain types of providers (e.g., high-quality teaching hospitals) is strong, the health plan's financial return to greater enrollment that derives from increased bargaining power is lower. 
A third potential source of economies of scale in health insurance relates to the amount of financial reserves that a health plan must hold to meet statutory requirements. For statistical reasons, the per-enrollee amount of financial reserves that a health plan is required to hold is less for health plans with larger enrollment bases.

If we define economies of scale as average costs falling with increased enrollment, then it is possible to test for the presence of economies of scale in health insurance using a data set on health plan costs, enrollment, and other characteristics. The following paragraphs report the results of such an analysis.

Most states require health insurance plans to file quarterly and/or annual reports with the state insurance commissioner using a common format created by the National Association of Insurance Commissioners (NAIC). These data are publicly available. The Weiss Ratings Company collects and compiles these data and sells reports based on them. In the data compiled by the Weiss Ratings Company are reports of total health plan administrative expenditures, total health plan medical expenditures, total health plan enrollment, and several characteristics of the health plan and the insurance products it markets.

The sample for analysis was created by selecting all health plans classified as HMOs in the Weiss data reporting positive enrollment in 2001. These selection criteria yielded a sample size of 439 health plans. Health plans that enrolled Medicare beneficiaries (eleven plans) or Medicaid beneficiaries (sixty plans) exclusively were dropped from the analysis. Health plans reporting fewer than 5,000 enrollees (twentyseven plans, five of which were Medicaid-only or Medicare-only plans) were also dropped from the sample. The remaining health plans were matched with the InterStudy database to collect additional information about the plans (321 matches out of the final Weiss sample of 347). Missing data for variables used as regressors led to a final sample size of 299 plans.

Figures 5.4 and 5.5 show substantial variation among health plans in administrative and medical expenses per member. The correlation between administrative and medical expenses is positive but not very large (correlation coefficient $=0.55$ ). There is no reason to expect that economies of scale in administrative expenses would be the same as economies of scale in medical expenses. In fact, the earlier discussion suggests different sources of economies of scale in the two types of expenditures. For this reason, separate analyses were conducted to test 


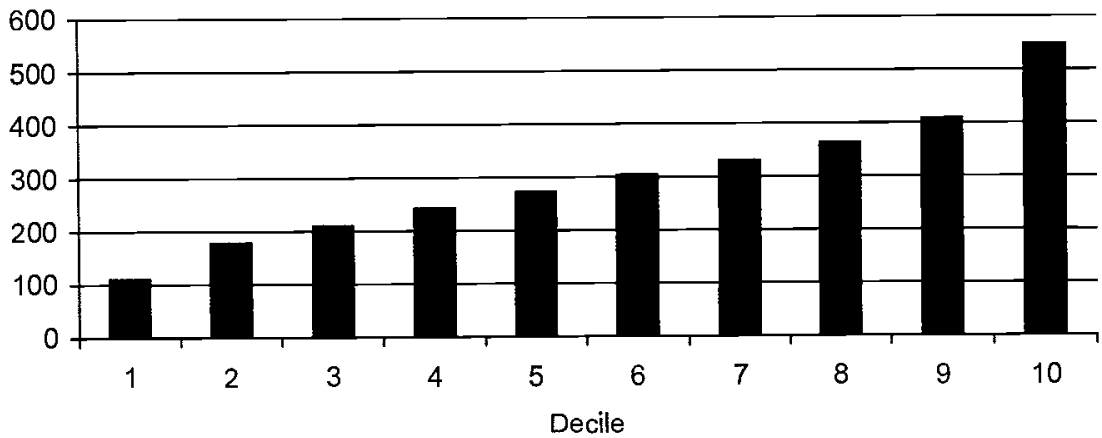

Figure 5.4

Average administrative expense

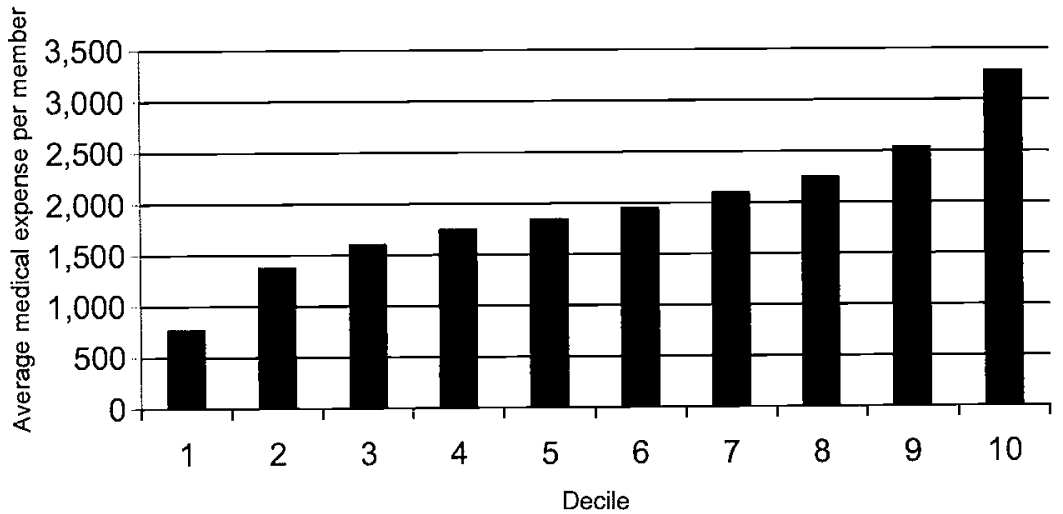

Figure 5.5

Average medical expense

for economies of scale in medical expenses and administrative expenses.

Figure 5.6 is a frequency distribution of health plan enrollment. This distribution is heavily skewed to the left; there is a relatively small number of plans with a very large enrollment (i.e., more than 500,000 enrollees). Note that 56 percent of health plans in this sample have HMO enrollment under 100,000 members (on the lower end of the plan size distribution). One indication of the presence of economies of scale is the distribution of medical and administrative expenses for health 


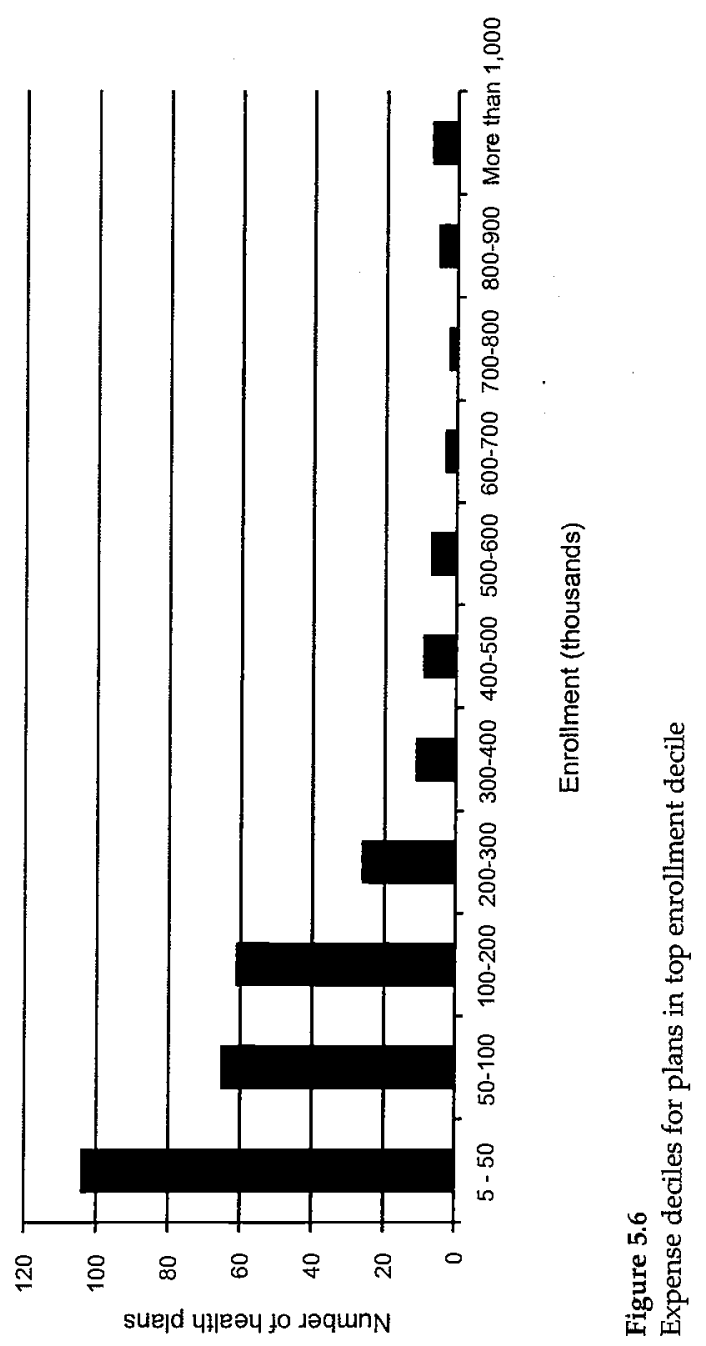


plans in the top enrollment decile. If economies of scale were present, one would expect to see an overrepresentation of these highenrollment plans in the lowest deciles for average per-member medical and administrative expenses. Figure 5.7 suggests that this expectation is not the case; the high-enrollment plans are evenly represented in the administrative expense deciles and overrepresented in the higher medical expense deciles.

Figure 5.8 is a scatterplot of administrative expenses per member compared to health plan enrollment. Although many health plans are clustered in the low enrollment/low administrative expense quadrant of the graph, there does appear to be a negative relationship between average administrative expense and enrollment. In contrast, there appears to be no relationship discernible from the scatterplot of per-member medical expenses and enrollment (see figure 5.9).

Several health plan characteristics could influence average administrative and medical expenses independent of scale. Accounting practices in nonprofit health plans tend to result in a larger number of expenses classified as administrative compared to those in for-profit health plans. The average administrative and medical expenditures may differ by product line because of the variation in costs of delivering care to enrollees in different market segments. The InterStudy data records enrollment in several different product lines, including commercial HMO, FEHBP, Medicare risk HMO, Medicare supplemental,

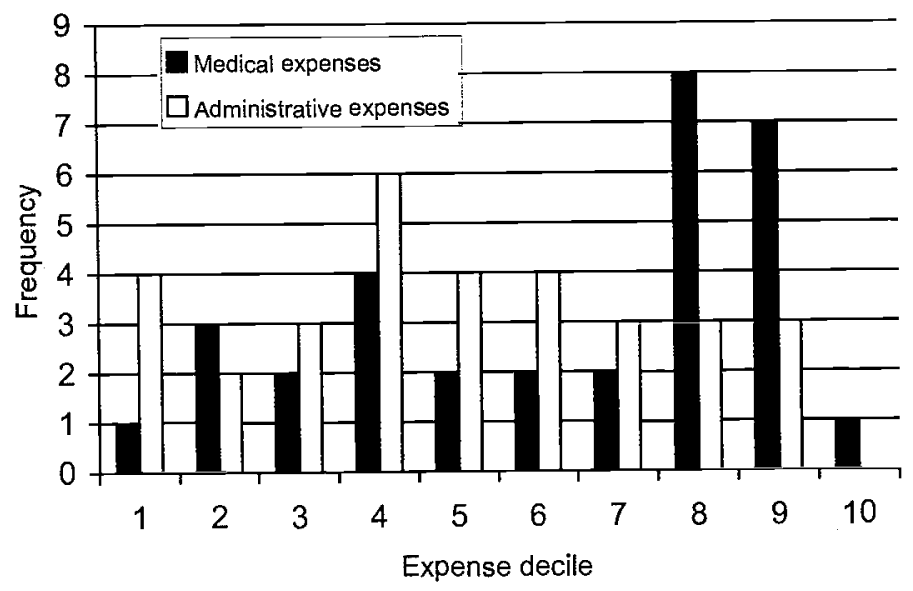

Figure 5.7

Expense deciles for plans in top enrollment decile 


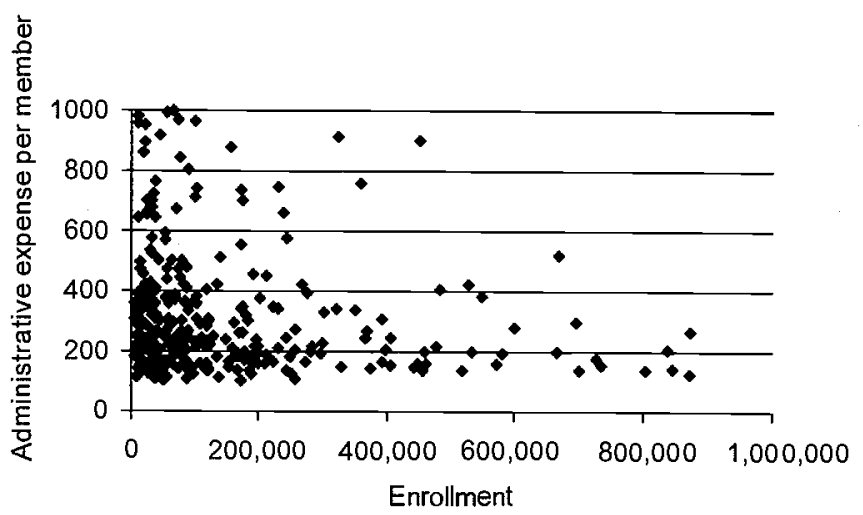

Figure 5.8

Plot of economies of scale in administrative expenses

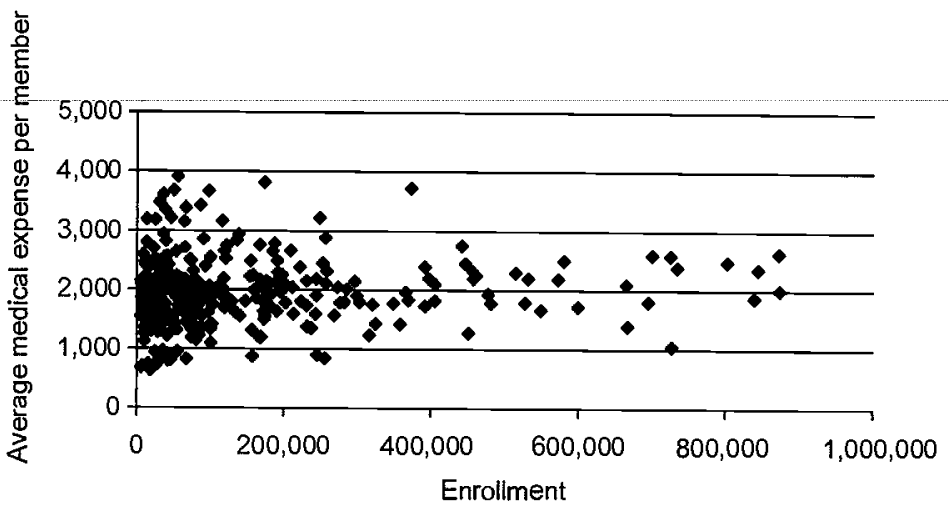

Figure 5.9

Plot of economies of scale in medical expenses

Medicaid risk HMO, POS, PPO, and FFS. In addition to the types of products offered by health plans, the total number of products may be positively related to average administrative costs. Because different product lines require product-specific investments in marketing, regulatory compliance, and provider networks, health plans concentrating their enrollment in fewer products are more likely to experience lower administrative expenses and possibly greater economies of scale.

Administrative and medical expenses per member may also be related to the health plan's provider network organization. There are 
four basic types of provider networks: (1) the staff model, in which physicians are employed by the health plan and are located in a small number of clinics; (2) the group model, in which health plans contract with physicians practicing in medical groups that may also contract with other health plans; (3) the Independent Physician Association (IPA) model, in which physicians in solo and group practice contract with an intermediary (the IPA), which in turn contracts with one or more health plans; and (4) the network model, in which health plans contract directly (not through an IPA) with a mix of solopractice and group-practice physicians. Today, the provider networks of most health plans are a mix of these four model types. The organization of the health plan's provider network is related to, but not identical to, the breadth of the network (measured as the number of physicians per member). Health plans with predominantly IPA-based networks also tend to have larger networks.

Health plans contracting with a large number of providers for a given membership size will likely have larger administrative costs per member because of the additional transaction costs involved in negotiating and executing a larger number of contracts. It is also plausible that health plans with larger provider networks (controlling for membership size) will have higher medical expenses per member for three reasons: (1) adverse selection, (2) the health plan will find it more difficult to control utilization with a larger network and a smaller number of enrollees per provider, and (3) the health plan will be less able to negotiate lower provider reimbursement rates when providers see few of the plan's enrollees.

In addition to the network characteristics discussed in previous paragraphs, the method of provider payment may influence average administrative and medical costs. Consider two primary reimbursement methods: fee-for-service and capitation. Fee-for-service reimbursement requires the processing of a claim and payment on a claim to an individual physician every time a service is delivered. In contrast, capitation reimbursement sometimes involves no filing and processing of individual claims and only a monthly per-member payment to the physician or the practice. In some cases, health plans employing capitation require providers to submit dummy claims that the health plan then processes, but the health plan still makes payments less frequently. It is also likely that capitation reduces per-member medical costs. 
In the last decade, there has been substantial consolidation of enrollment into a relatively small number of national and regional health plans. A statistical analysis of the relationship between local health plan enrollment and local health plan expenditures (both medical and administrative) that failed to account for affiliation with a national managed-care company might underestimate the true extent of economies of scale. ${ }^{17}$ Affiliation with a national or regional managed-care company should convey economies of scale to a local plan to the extent that the cost of centralized services (i.e., claims processing) can be spread over a national or regional enrollment base.

Finally, a health plan's medical and administrative expenses may depend on the characteristics of the local health care markets in which it operates. There is substantial geographical variation in the organization of the provider sector, regulatory environment, and the extent of mandated benefits that could lead to differences in health plan cost structures.

Any one of these health plan or market characteristics could have an impact on average health plan administrative and medical expenditures. To assess empirically whether economies of scale exist in health plan enrollment, it is necessary to control statistically for these other factors. Consequently a regression analysis was undertaken to assess the relationship between health plan enrollment and average per-member administrative and medical expenses.

Table 5.9 presents the results of two regression analyses. In column 2 , the dependent variable is administrative costs per member; in column 3 , the dependent variable is average medical costs per member. A fixed effect for the health plan's primary state of operation (the state in which the health plan had the greatest enrollment) was included in each regression to control for regional variation in expenses. The estimated coefficients presented in columns 2 and 3 indicate that small but significant economies of scale are present in both administrative expenses and medical expenses. Because both the dependent variable and the enrollment variables are measured in natural logs, the coefficients on the enrollment variables in the regression may be interpreted as elasticities (e.g., the percentage change in administrative expenses associated with a one percentage change in enrollment). The estimated 


\section{Table 5.9}

Economies of scale-regression results

\begin{tabular}{|c|c|c|}
\hline \multirow[b]{2}{*}{ Independent variable } & \multicolumn{2}{|c|}{ Dependent variable log } \\
\hline & $\begin{array}{l}\text { Administrative } \\
\text { expense } \\
\text { per member }\end{array}$ & $\begin{array}{l}\text { Medical } \\
\text { expense } \\
\text { per member }\end{array}$ \\
\hline \multicolumn{3}{|l|}{ Percentage enrollment share- } \\
\hline Medicare risk & ${ }^{\mathrm{a}} 1.54(0.22)$ & ${ }^{\mathrm{a}} 1.78(0.26)$ \\
\hline Medicaid risk & $c_{-0.28(0.16)}$ & $-0.27(0.18)$ \\
\hline Direct pay & $0.07(0.41)$ & ${ }^{\mathrm{a}}-0.83(0.28)$ \\
\hline FEHBP & $-0.25(0.45)$ & $0.14(0.34)$ \\
\hline Commercial HMO & $-0.16(0.14)$ & $-0.30(0.20)$ \\
\hline POS & ${ }^{\mathrm{a}} 0.74(0.21)$ & ${ }^{\mathrm{b}} 0.44(0.22)$ \\
\hline PPO & $0.04(0.14)$ & ${ }^{c}-0.56(0.29)$ \\
\hline Supplemental Medicare & $2.36(1.75)$ & $0.85(0.97)$ \\
\hline FFS & $0.65(0.55)$ & $-0.29(0.41)$ \\
\hline \multicolumn{3}{|l|}{ Percentage provider payment- } \\
\hline Capitation & $-0.12(0.14)$ & $-0.12(0.12)$ \\
\hline Fee-for-service & $0.05(0.09)$ & $-0.03(0.13)$ \\
\hline Provider payment imputation & $c_{-0.31(0.19)}$ & $-0.31(0.24)$ \\
\hline Product Herfindahl & $0.12(0.18)$ & $0.28(0.20)$ \\
\hline Age of plan & $0.00(0.00)$ & $0.00(0.00)$ \\
\hline Physicians per 1,000 enrollees & ${ }^{\mathrm{a}} 475.34(152.54)$ & a-796.89 (208.74) \\
\hline Log of enrollment & ${ }^{b}-0.05(0.03)$ & ${ }^{b}-0.64(0.03)$ \\
\hline $\begin{array}{l}\text { Log of national managed-care } \\
\text { enrollment }\end{array}$ & $-0.00(0.01)$ & $0.00(0.00)$ \\
\hline $\begin{array}{l}\text { Log of regional managed-care } \\
\text { enrollment }\end{array}$ & $0.00(0.01)$ & $-0.01(0.01)$ \\
\hline For-profit HMO & b $0.16(0.08)$ & $-0.01(0.06)$ \\
\hline $\begin{array}{l}\text { Percentage of enrollment in } \\
\text { IPA or mixed model }\end{array}$ & ${ }^{\mathrm{b}} 0.14(0.06)$ & b0.13 (0.06) \\
\hline Number of products & $0.00(0.02)$ & ${ }^{\mathrm{a}} 0.07(0.02)$ \\
\hline Number of states & $0.13(0.11)$ & $0.15(0.14)$ \\
\hline Constant & a5.82 (0.29) & a7.85 (0.29) \\
\hline State dummy variables & Included & Included \\
\hline Number of observations & 299 & 299 \\
\hline R-squared & 0.50 & 0.54 \\
\hline
\end{tabular}

${ }^{a} p \leq 0.01$.

${ }^{b} p \leq 0.05$.

$c_{p} \leq 0.10$.

Note: Standard errors in parentheses. 
coefficient on within-plan enrollment is -0.05 for administrative expenses and -0.06 for medical expenses, indicating that a one percentage increase in the health plan's enrollment is associated with a .05 to .06 percentage point decrease in average administrative and medical costs, respectively. These estimated relationships are depicted in figures 5.10 and 5.11 .

Recall that, for plans affiliated with national or regional managedcare companies, the total national or regional enrollment was entered

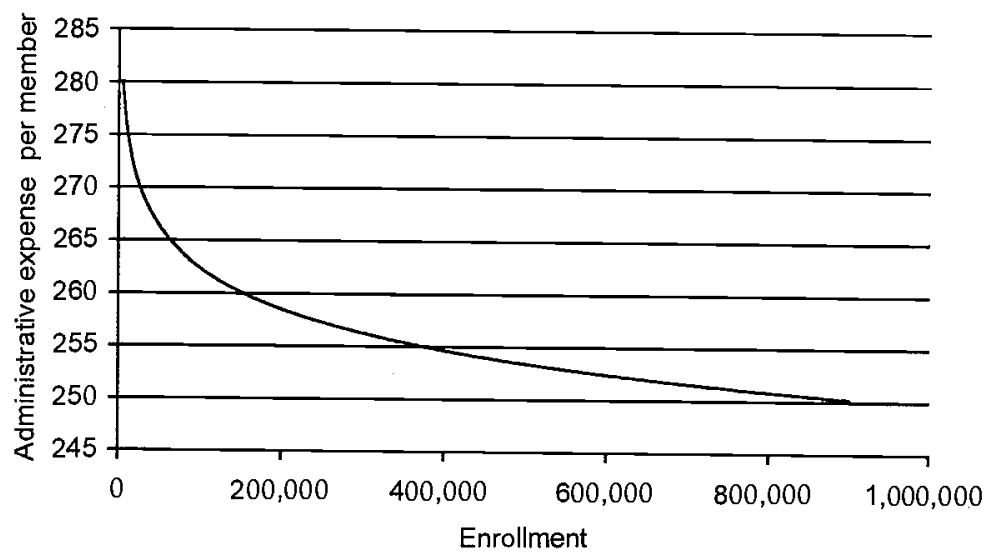

Figure $\mathbf{5 . 1 0}$

Estimated economies of scale in administrative expenditures

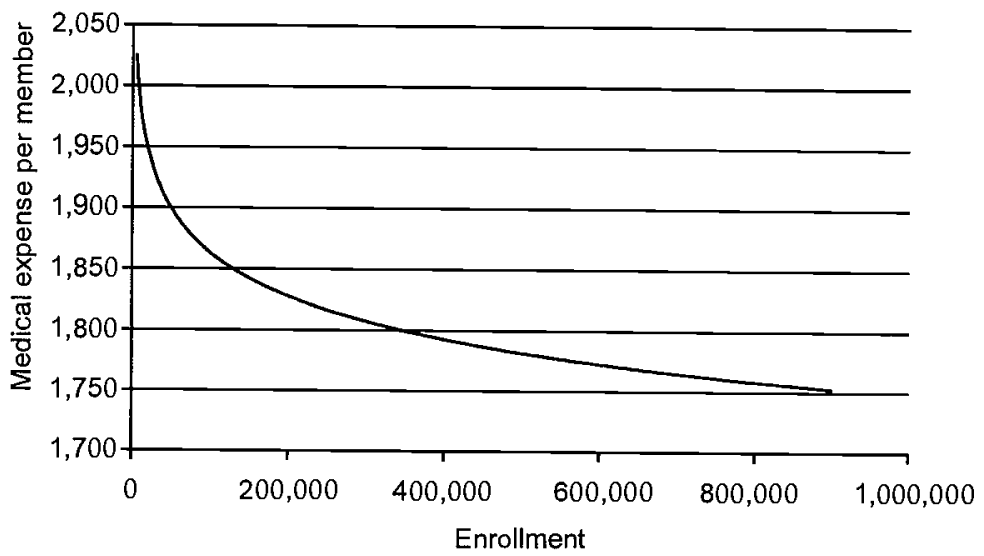

Figure 5.11

Estimated economies of scale in medical expenses 
separately into the regression. The coefficients on these variables indicate the extent to which the additional scale (enrollment) present in a national or regional managed-care company is associated with higher or lower administrative expenses per member in the local plan. The point estimates on these enrollment variables in both regressions are essentially zero and insignificant.

Given the topic of this paper, it is worthwhile to note that this regression analysis suggests that nonprofit health plans have significantly higher per-member administrative costs but not significantly different average medical costs. As noted earlier, however, this finding may be an artifact of nonprofit accounting customs.

In summary, the regression analysis finds evidence of modest economies of scale in both administrative and medical costs. The estimated economies of scale are nearly exhausted at an enrollment of roughly 800,000 . Only twelve health plans in our sample have an enrollment greater than this number. In addition, it appears that there are no additional economies of scale to be gained through membership in a regional or national managed-care company.

Quality of Care. Consumers, providers, managers, and researchers all acknowledge that quality in health care is multidimensional and difficult to measure. These characteristics of quality lead to difficulties in contracting for a specified level of quality and to challenges in holding individuals and organizations accountable for the quality of health care services delivered. Quality of care arises as an issue in health plan conversions because of the potential opportunity and financial incentive for a for-profit health plan to skimp on the aspects of quality that are difficult for consumers to observe and verify.

Differences in quality between health plans do exist and are sometimes large. For example, the Centers for Disease Control estimates that nearly 16 million Americans have diagnosed or undiagnosed diabetes. If not properly managed, diabetes can have devastating health consequences and can consume lots of expensive health care resources. To manage their disease, people with diabetes and their physicians must know the level of the patient's hemoglobin $\mathrm{A} 1 \mathrm{c}(\mathrm{HbA} 1 \mathrm{c})$, and this information is obtained through a simple blood test. In the sample of plans reporting data to the National Committee on Quality Assurance in 2000, the percentage of diabetic plan members who had their $\mathrm{HbA1c}$ tested ranged from 24 percent to 97 percent. This range suggests substantial variation in performance and ample room for improvement. 
Research has shown that health plans that undertake diabetes disease management programs can effect substantial improvements in care and short-term outcomes for people with diabetes.

Published health services research documents correlations between health plan performance on some quality measures and various health plan characteristics. ${ }^{18}$ Although the root causes of these patterns are not well understood, local independent and nonprofit health plans frequently outperform for-profit, publicly traded, national managed-care plans. These findings are important for public officials to consider as they determine whether particular conversions are in the interest of health care consumers. In the following section, I compare the performance of CareFirst, Wellpoint, and other health plans operating in their respective markets on various measures of health plan quality.

Measures of Health Plan Quality. In 1997, the National Committee on Quality Assurance (NCQA) began reporting the performance of some health plans on a selected set of quality measures. This set of measures (the Health plan and Employers Data Information Set [HEDIS]) was chosen by a group of health care purchasers and medical professionals and has been expanded over the years. Health plans voluntarily submit performance data (most is audited) to the NCQA, which then publishes these data in a product called Quality Compass. Consumers and employers have used these data to help them make health care purchasing decisions; academic researchers have used these data to study the causes of variation in health plan quality.

The HEDIS measures convey information about the extent to which the health plan's enrollees are obtaining preventive services and diagnostic tests necessary for managing certain chronic diseases. (See table 5.10 for a list of HEDIS measures used in the analyses presented in this paper.) The HEDIS set also includes a few measures of health care

Table 5.10

Definitions of HEDIS quality measures

Adolescent

immunization rates

Rate of advising smokers to quit
Estimates the percentage of adolescent health plan members that have been verified to have received all required doses of several vaccines by their thirteenth birthday.

Measures the percentage of eligible health plan members who were advised to quit smoking during a visit with a physician during the measurement year. 
Table 5.10

(continued)

Use of appropriate medications for people with asthma

Beta blocker treatment after a heart attack

Breast cancer screening rates

Cervical cancer screening rates

Childhood immunization rates

Chlamydia screening rates

Comprehensive diabetes care

Follow-up after mental illness, 7-day and 30 -day rates

Prenatal and postpartum care rates
Evaluates whether health plan members who are suffering from persistent asthma are being prescribed medications deemed acceptable by the National Heart, Lung and Blood Institute as primary therapy for long-term control of asthma.

Estimates the percentage of members age 35 and older who are hospitalized and discharged from the hospital after surviving a heart attack (defined as an acute myocardial infarction [AMI]) and who received a prescription for a beta blocker.

Estimates the percentage of women age 52 through 69 who are enrolled in a health plan and who had a mammogram during the measurement year or the year prior to the measurement year.

Estimates the percentage of women age 21 to 64 who were enrolled in a health plan and who had an Papanicolau (Pap) test during the measurement year or the two years prior.

Estimates the percentage of children who were enrolled in managed-care plans, turned two years old during the measurement year, and had received vaccinations: (1) four doses of DTP or DtaP (diptheria-tetanus), (2) three doses of OPV or IPV (polio), (3) one dose of MMR (measles-mumps-rubella), (4) two doses of $\mathrm{Hib}$ (Haemophilus influenza), (5) three doses of Hepatitis B, and (6) one dose of VZV (chicken pox).

Estimates the percentage of sexually active female plan members who had at least one test for chlamydia during the measurement year. The measure is collected separately for women age 16 to 20 and 21 to 26 .

Measure set includes several important features of effective, multphasic management of diabetes and its complications. The measure estimated the percentage of health plan members with Type 1 and Type 2 diabetes who were 18 to 75 years old and during the measurement year had (1) a hemoglobin A1c (HbAlc) test, (2) poorly controlled $\mathrm{HbA} 1 \mathrm{c}$ (level greater that $9.5 \%$ ), (3) a serum cholesterol level (LDL-C) screening, (4) their cholesterol level (LDL-C) controlled to less than $130 \mathrm{mg} / \mathrm{dl}$, (5) an eye exam, and (6) a screening for kidney disease.

Indicates the percentage of health plan members age six and older who received inpatient treatment for a mental health disorder and had an ambulatory or day/night follow-up visit after being discharged.

Measures timeliness of prenatal care and postpartum care. 
outcomes for the health plan's enrolled population that signal how well the health plan is doing overall at helping its members stay healthy.

The second set of measures of health plan quality is derived from a survey instrument called the Consumer Assessment of Health Plans Survey (CAHPS); CAHPS data are included in Quality Compass. The survey is administered by an independent party to a random sample of the health plan's enrollees to collect data on consumers' experiences in seeking and obtaining health care. Health plans often submit their performance on CAHPS to organizations that publish comparative health plan data (such as the federal government, the NCQA, and local health care purchasing groups). The federal government has mandated the collection and reporting of these survey data for Medicare beneficiaries enrolled in Medicare HMOs.

The CAHPS instrument generates hard-to-find data on the quality of enrollees' interactions with providers and health plans. (See Table 5.11 for a list of CAHPS measures used in the analyses presented in this report.) Health plans can take many actions to facilitate consumers' access to care, to educate consumers about and involve them in their own health care, to ease the administrative burden of dealing with insurance claims, and to select and support a provider network that routinely delivers high-quality patient-friendly care. The CAHPS measures provide health plans with an opportunity to distinguish themselves in these areas.

HEDIS Comparisons. CareFirst operates three separate health plans in the mid-Atlantic region that reported 1999 HEDIS data to NCQA (the data are published in Quality Compass 2000): CapitalCare Inc., Delmarva Health Plan Inc., and FreeState Health Plan Inc. In the analyses that follow, an average score is computed for all three CareFirst plans weighted by HMO enrollment. Wellpoint operates the Blue Cross of California (BC-CA) health plan in California; this plan reported a limited set of 1999 HEDIS data to NCQA. Performance on HEDIS measures may be influenced by some factors beyond the health plan's control, such as sociodemographic characteristics of the plan's membership, local organization of providers, and state health initiatives. To control for variation in some of these factors across markets, the HEDIS scores of each plan have been adjusted for the region of the country in which the health plan operates.

Table 5.12 presents HEDIS data comparing the average performance of the CareFirst plans to Wellpoint's California plan and to the national 
Table 5.11

Definitions of CAHPs quality measures

\begin{tabular}{ll}
\hline Getting care quickly & $\begin{array}{l}\text { Measures timeliness of services received from health care } \\
\text { providers in the last twelve months. }\end{array}$
\end{tabular}

Claims processing Measures managed-care enrollees' experiences with submitting claims to their health plans in the last twelve months.

Customer service Measures how difficult it was for enrollees in managed care plans to obtain information and to complete paperwork in the last twelve months.

How well doctors communicate

Measures the consumers' experiences while seeing a doctor or health care provider in the last twelve months.

Getting needed care

A composite measure consisting of several questions related to consumers' experiences in attempting to obtain care from doctors and specialists.

Courtesy of office staff

Measures managed-care enrollees' perception of quality of customer service when interacting with staff in their doctors' offices and clinics in the last twelve months.

Overall rating of doctor

Respondents were asked to rate their personal doctor or nurse with 0 ("worst personal doctor or nurse possible") to 10 ("best personal doctor or nurse possible").

Overall rating of specialist

Respondents who had seen a specialist physician in the last twelve months were asked to rate their specialist with 0 ("worst specialist possible") to 10 ("best specialist possible").

Overall rating of health plan

Overall rating of health care

Respondents were asked to rate their health plan with 0 ("worst health plan possible") to 10 ("best health plan possible").

Respondents were asked to rate the quality of the health care they received in the last twelve months, with 0 ("worst health care possible") to 10 ("best health care possible").

average on three types of measures: preventive care, chronic care, and mental health care. CareFirst performs least well on the preventive-care measures; its scores exceed the national average on four out of ten measures, and BC-CA outperforms CareFirst on six out of the seven measures for which data were submitted by BC-CA. The second group of measures relates to care for enrollees with chronic disease. BC-CA reported only one out of eight measures in this group, and its performance on this measure falls significantly below CareFirst's performance. CareFirst outperforms the national average on six out of eight measures in the chronic-care category. Finally, in the third group of measures relating to mental health care, CareFirst outperforms BC-CA on the two measures for which Wellpoint submitted data. CareFirst outperformed the national average on three out of five measures in this category. 
Table 5.12

Comparison of CareFirst and Wellpoint plans on HEDIS measures

\begin{tabular}{|c|c|c|c|c|c|}
\hline HEDIS measures & CareFirst & BC-CA & National & $\begin{array}{l}\text { National } \\
\text { Public } \\
\text { FP }\end{array}$ & $\begin{array}{l}\text { National } \\
\text { standard } \\
\text { deviation }\end{array}$ \\
\hline \multicolumn{6}{|l|}{ Preventive care } \\
\hline Child immunization 1 & 77.6 & 68.4 & 65.9 & 65.7 & 13.0 \\
\hline Child immunization 2 & 65.6 & & 48.7 & 47.6 & 11.7 \\
\hline Adol immunization 1 & 24.7 & 27.4 & 33.2 & 28.7 & 17.7 \\
\hline Adol immunization 2 & 16.7 & & 15.6 & 12.4 & 11.9 \\
\hline Advice to quit smoking & 70.1 & 60.8 & 64.7 & 62.3 & 6.9 \\
\hline Breast cancer screening & 70.6 & 75.9 & 74.9 & 72.6 & 5.9 \\
\hline Cervical cancer screening & 68.4 & 70.1 & 73.7 & 71.8 & 7.7 \\
\hline Prenatal care & 85.1 & 87.3 & 86.4 & 86.8 & 11.1 \\
\hline Checkup after delivery & 69.3 & 79.1 & 74.6 & 73.7 & 11.8 \\
\hline Beta blockers & 85.5 & 86.9 & 86.5 & 87.2 & 9.7 \\
\hline \multicolumn{6}{|l|}{ Chronic care } \\
\hline Cholesterol rate & 18.8 & & 47.8 & 45.1 & 15.0 \\
\hline Cholesterol screening & 70.7 & & 70.2 & 67.8 & 11.1 \\
\hline HbA1c test & 79.1 & & 77.3 & 76.3 & 8.9 \\
\hline Diabetic eye exam & 58.8 & 39.5 & 48.5 & 44.7 & 14.3 \\
\hline Lipid profile & 68.0 & & 70.4 & 69.7 & 9.9 \\
\hline Lipid control & 44.8 & & 38.6 & 35.8 & 9.6 \\
\hline Nephropathy monitoring & 38.1 & & 37.3 & 35.7 & 14.4 \\
\hline HbA1c control & 79.7 & & 58.0 & 55.3 & 14.3 \\
\hline \multicolumn{6}{|l|}{ Mental health care } \\
\hline Mental illness-7 days & 60.6 & 45.0 & 49.2 & 49.6 & 14.7 \\
\hline Mental illness -30 days & 72.0 & 50.5 & 72.3 & 70.9 & 13.7 \\
\hline Depression contact & 8.7 & & 21.3 & 19.9 & 10.3 \\
\hline Depression, acute & 68.9 & & 60.3 & 61.3 & 9.5 \\
\hline Depression, continuous & 45.2 & & 43.6 & 43.2 & 10.4 \\
\hline
\end{tabular}

These comparisons between the CareFirst plans and the WellpointCA plan suggest that each of these plans has strengths and weaknesses and that neither plan dominates the other on HEDIS measures. Note that at least one CareFirst plan reported data for every HEDIS measure (twenty-three measures in all), while the Wellpoint-CA plan reported data on just less than half of the measures. The collection and public reporting of plan performance on HEDIS measures signals a plan's commitment to improving health care quality.

Table 5.13 facilitates a comparison of performance by CareFirst and Wellpoint-CA on HEDIS measures to the Kaiser plans operating in the CareFirst and Wellpoint-CA markets. The Kaiser Foundation is the holding company for the only truly national, nonprofit, managed-care 
Table 5.13

Comparison of BCBS plans to Kaiser plans on HEDIS measures

\begin{tabular}{lllll} 
& CareFirst & $\begin{array}{l}\text { Kaiser } \\
\text { Mid-Atlantic }\end{array}$ & BC-CA & $\begin{array}{l}\text { Kaiser } \\
\text { California }\end{array}$ \\
\hline Preventive care & & & & \\
Child immunization 1 & 77.6 & 88.6 & 68.4 & 76.2 \\
Child immunization 2 & 65.6 & 76.5 & & 69.5 \\
Adol immunization 1 & 24.7 & 48.4 & 27.4 & 34.5 \\
Adol immunization 2 & 16.7 & 50.2 & & 16.6 \\
Advice to quit smoking & 70.1 & 67.6 & 60.8 & 68.0 \\
Breast cancer screening & 70.6 & 79.4 & 75.9 & 75.8 \\
Cervical cancer screening & 68.4 & 88.6 & 70.1 & 77.4 \\
Prenatal care & 85.1 & 86.9 & 87.3 & 89.5 \\
Check-up after delivery & 69.3 & 80.1 & 79.1 & 83.2 \\
Beta blockers & 85.5 & 98.3 & 86.9 & 89.7 \\
Chronic care & & & & \\
Cholesterol rate & 18.8 & 67.5 & & 45.2 \\
Cholesterol screening & 70.7 & 75.3 & & 78.4 \\
HbAlc test & 79.1 & 85.9 & & 77.5 \\
Diabetic eye exam & 58.8 & 87.7 & 39.5 & 64.0 \\
Lipid profile & 68.0 & 69.2 & & 70.5 \\
Lipid control & 44.8 & 41.9 & & 41.2 \\
Nephropathy monitoring & 38.1 & 74.8 & & 55.2 \\
HbA1c control & 79.7 & 71.1 & & 55.1 \\
Mental health care & & & & \\
Mental illness-7 days & 60.6 & 65.5 & 45.0 & 62.6 \\
Mental illness-30 days & 72.0 & 79.2 & 50.5 & 83.3 \\
Depression contact & 8.7 & 34.6 & & 28.4 \\
Depression, acute & 68.9 & 63.8 & & 68.6 \\
Depression, continuous & 45.2 & 46.1 & & 58.2 \\
\hline & & & &
\end{tabular}

plan in the United States. All other nonprofit managed-care companies have only a local or a regional presence. The Kaiser Foundation plans in California and the mid-Atlantic region reported a full set of 1999 HEDIS data to NCQA.

Comparing the second and third columns of table 5.13, note that Kaiser of the Mid-Atlantic outperforms CareFirst on nearly every HEDIS measure (nineteen out of twenty-three). Second, comparing the third and fourth columns of the table, note that the Kaiser plans of California outperform Wellpoint on nearly every measure for which Wellpoint reported data (ten out of eleven). Finally, Kaiser Mid-Atlantic outperforms Kaiser California on sixteen out of the twenty-three measures. This comparison of the two Kaiser plans raises the concern that the method used for controlling for systematic geographical variation was 
not completely successful. However, the magnitude of the differences between the Kaiser plans and CareFirst and Wellpoint plans suggests systematic differences even within a region.

In summary, three major conclusions emerge from these comparisons on HEDIS measures. First, the CareFirst and the BC-CA plans each have strengths and weaknesses on HEDIS measures, and neither plan dominates the other. BC-CA compares favorably on preventivecare measures, while the CareFirst plans compare favorably on chronic-care and mental-health-care measures. Second, both the $\mathrm{BC}-\mathrm{CA}$ plan and the CareFirst plans are outperformed by the Kaiser plans in their respective markets on HEDIS measures.

CAHPS comparisons. This section of the report presents comparisons of the performance of several health plans on the set of CAHPS composite measures published in Quality Compass 2000. Examination of table 5.14 shows that the CareFirst plans outperform the BC-CA plan on eight out of ten CAHPS measures (the plans are essentially equal on two measures). The largest differences between the health plans' performance relate to access to care-getting care quickly and getting needed care. Table 5.13 also facilitates a comparison of the BC-CA and CareFirst plans to the national average. BC-CA performs below the

Table 5.14

Comparison of CareFirst and Wellpoint plans on CAHPS measures

\begin{tabular}{|c|c|c|c|c|c|}
\hline & CareFirst & $\mathrm{BC}-\mathrm{CA}$ & National & $\begin{array}{l}\text { National } \\
\text { Public } \\
\text { FP }\end{array}$ & $\begin{array}{l}\text { National } \\
\text { standard } \\
\text { deviation }\end{array}$ \\
\hline Claims processing & 83.0 & 81.1 & 79.1 & 76.4 & 9.2 \\
\hline Courteous staff & 90.7 & 88.8 & 91.6 & 90.7 & 2.7 \\
\hline Customer service & 66.0 & 64.9 & 65.8 & 63.0 & 6.3 \\
\hline Getting care quickly & 78.1 & 67.6 & 79.2 & 77.8 & 5.4 \\
\hline Getting needed care & 77.2 & 70.6 & 75.4 & 72.7 & 6.8 \\
\hline $\begin{array}{l}\text { Communication with } \\
\text { doctor }\end{array}$ & 91.2 & 86.2 & 89.8 & 88.9 & 2.9 \\
\hline $\begin{array}{l}\text { Overall health care } \\
\text { rating }\end{array}$ & 68.5 & 68.4 & 71.1 & 68.8 & 6.1 \\
\hline $\begin{array}{l}\text { Overall health plan } \\
\text { rating }\end{array}$ & 59.2 & 56.0 & 58.0 & 53.5 & 8.4 \\
\hline Overall PCP rating & 74.0 & 74.2 & 73.5 & 73.2 & 4.4 \\
\hline $\begin{array}{l}\text { Overall specialist } \\
\text { rating }\end{array}$ & 75.5 & 67.4 & 75.3 & 74.6 & 4.8 \\
\hline
\end{tabular}


national average on eight out of ten CAHPS measures; CareFirst performs better than the national average on seven out of ten measures. Also note that the average for national, publicly traded, for-profit health plans is below the average for all plans nationally.

The Kaiser Mid-Atlantic plan outperforms the CareFirst plans on two out of the ten CAHPS measures, in contrast, the Kaiser California plan outperforms the BC-CA plan on nine out of ten measures (see table 5.15).

In summary, the analysis of CAHPS quality measures suggests that CareFirst members have had more favorable experiences in obtaining health care services compared to the Wellpoint plan in California. Comparisons to local Kaiser plans in each market reinforce the findings of the head-to-head comparison of BC-CA and the CareFirst plans.

\section{Postscript in the CareFirst Conversion Case}

The Maryland insurance commissioner, Stephen Larsen, initiated hearings on CareFirst's conversion petition prior to the insurance commissioners in the District of Columbia and Delaware. As part of the Maryland hearings and in anticipation of formal hearings in D.C., several consultants were hired to value CareFirst; most of these valuations exceeded Wellpoint's offer of $\$ 1.3$ billion. In the course of the hearings, concerns were also raised about the process used by the board of

Table 5.15

Comparison of CareFirst and Wellpoint plans to Kaiser plans on CAHPS measures

\begin{tabular}{lllll} 
& $\begin{array}{l}\text { Care- } \\
\text { First }\end{array}$ & $\begin{array}{l}\text { Kaiser } \\
\text { Mid- } \\
\text { Atlantic }\end{array}$ & BC-CA & $\begin{array}{l}\text { Kaiser } \\
\text { California }\end{array}$ \\
\hline Claims processing & 83.0 & 66.0 & 81.1 & 79.1 \\
Courteous staff & 90.7 & 90.5 & 88.8 & 90.3 \\
Customer service & 66.0 & 77.4 & 64.9 & 73.0 \\
Getting care quickly & 78.1 & 80.0 & 67.6 & 76.0 \\
Getting needed care & 77.2 & 76.2 & 70.6 & 78.8 \\
Communication with doctor & 91.2 & 82.2 & 86.2 & 87.0 \\
Overall health care rating & 68.5 & 65.2 & 68.4 & 70.3 \\
Overall health plan rating & 59.2 & 57.3 & 56.0 & 64.5 \\
Overall PCP rating & 74.0 & 72.4 & 74.2 & 75.0 \\
Overall specialist rating & 75.5 & 71.3 & 67.4 & 75.3 \\
\hline
\end{tabular}


CareFirst to solicit bids and the board's selection of the Wellpoint offer. Finally, the terms of the deal appeared to enrich CareFirst executives personally.

On March 5, 2003, Commissioner Larson denied the petition by CareFirst to convert to for-profit status and to be acquired by Wellpoint. Both the District of Columbia and Delaware suspended their conversion proceedings. In reviewing the research and evidence, Commissioner Larson found three reasons to deny the conversion. First, he found that CareFirst had been operating like a for-profit company despite legal requirements to adhere to a nonprofit, public-interest mission. Second, he found that the CareFirst board failed to consider CareFirst's obligations as a nonprofit entity, and that the board did not negotiate the best price for CareFirst and was offering to sell at less than fair market value. Third, and finally, Commissioner Larson found that CareFirst did not demonstrate a need to convert to for-profit status to remain viable.

On April 8, 2003, the Maryland legislature ratified Larsen's decision and passed Senate bill 772. In essence, the bill is an attempt to restructure CareFirst as a functioning nonprofit health plan that will execute its mission. It calls for replacement of all Maryland-appointed CareFirst board members and compensation to be paid to board members, officers and employees to be comparable to similar positions in other nonprofit organizations. It establishes a joint nonprofit health service plan oversight committee to oversee CareFirst operations in a manner consistent with the interests of Maryland citizens, and it prohibits the acquisition of CareFirst for five years. In terms of health plan conduct, it requires that CareFirst (1) offer health care products in the individual and small-group markets, (2) administer and subsidize the Senior Prescription Drug Program in Maryland, and (3) devote any remaining avoided taxes to a public-interest project.

Far from closing the chapter on CareFirst's petition to convert, the Maryland legislation sparked controversy in the District of Columbia and action by some of the parties. The D.C. insurance commissioner claimed that the Maryland legislation could render the CareFirst plan in D.C. uncompetitive and not viable. The Blue Cross and Blue Shield Association revoked CareFirst's use of the BCBS brand. Finally, Wellpoint abandoned hopes of acquiring CareFirst and announced a deal to acquire the publicly traded holding company of BCBS of Wisconsin. 


\section{Summary and Suggestions for Future Research}

The health insurance industry has undergone substantial consolidation in recent years. This consolidation has coincided with, and in part been caused by, the growth of for-profit, publicly traded health insurance companies. These changes in health insurance markets have led industry and government leaders to question the current and potential role of nonprofit health plans. Some of these leaders believe that many, if not all, nonprofit health plans are already conducting themselves like their for-profit competitors and hence question the value of giving a tax exemption to these plans. Among people holding this view, however, there is little agreement about what should be done when these nonprofit health plans apply for conversion to for-profit public-stock companies. The lack of agreement derives from uncertainty about the viability of nonprofit health plans in a market dominated by for-profit plans and from ignorance about governance structures that could hold nonprofit health plans (or foundations) accountable to a public-interest mission.

The governance structures necessary to implement a public-interest mission consistently, and the viability of a nonprofit health plan executing such a mission, form the foundation on which the welfare consequences of potential changes in the conduct of a converting health plan should be evaluated. The welfare consequences of conduct changes must be evaluated in conjunction with the set of feasible alternative institutions for executing the public-interest mission. For example, it may be that a converting health plan would abandon unprofitable markets and raise premiums in other markets. Denying the petition to convert does not ensure, however, that unprofitable markets will be better served or that premium increases will be limited to cost increases; furthermore, it does not ensure that the nonprofit plan will survive or otherwise be financially capable of these tasks.

Health policy makers are in need of economic research to answer a few basic questions. First, how might unregulated market competition thwart a nonprofit health plan in executing its mission? In other words, what are the threats to viability? Second, what market interventions might ensure viability of the mission? Only after these questions are answered can one then pose the social value question: is the mission worth it? To answer this question, economists and others will have to assess the costs and benefits of alternative regulatory institutions. Finally, creating a conducive environment for a nonprofit health plan is 
not sufficient. Policy makers need empirical and theoretical research on the types of governance structures that will guide faithful execution of the nonprofit health plan's mission.

While research and experience have identified important gaps in our knowledge, economic analyses have made valuable contributions to the evaluation of conversions. The case study analysis of CareFirst confirms prior research findings that differences in health plan quality related to ownership structure exist. To enhance the usefulness of these findings, we need to understand the causal mechanisms underlying the correlation between quality and health plan characteristics. We do not know, for instance, whether nonprofit plans have higher quality on average because they consider this part of their mission and allocate surplus to achieve this higher quality or because the organization of nonprofit health plans differs from for-profit health plans in ways that facilitate higher quality at the same cost. Of course, these explanation are not the only two possible, and additional research is needed to identify and articulate the mechanisms by which health plans influence quality.

The analyses of the economies of scale presented in this chapter have generated evidence of the relationship between health plan size and average costs. In the case of CareFirst, with over 3.1 million members, little or no cost savings seems to be achieved through expanded enrollment. This finding calls into question CareFirst's claim that it needs greater access to capital to be able to finance future health plan acquisitions.

Finally, the market structure analyses demonstrate the importance of examining distinct product and consumer market segments. Market-share analyses for the District of Columbia suggest that the CareFirst plan, GHMSI, possesses substantial market power in some segments. Whether GHMSI was exercising self-restraint in pricing the policies it sold in this market was not possible to determine from the available data. Note that health plan costs by product would be necessary to assess price-cost margins and that cost data for every product would be necessary to evaluate a health plan's strategy to cross-subsidize.

The findings presented in this paper are subject to several caveats and limitations. First, because of its limited scope, several health policy issues are not addressed by this study. One example is the participation by nonprofit health plans in traditionally underserved markets. In addition, lack of data prohibited a careful examination of health plan 
underwriting practices and health plan-provider relationships. Second, it was beyond the scope of the CareFirst case study to examine the extent to which CareFirst was fulfilling its mission, the long-term viability of such a mission, and the governance structures that would facilitate implementation of this mission. ${ }^{19}$ More generally, this case study analysis highlights the need for research elucidating the characteristics of markets that influence the viability of nonprofit health plans and the scope for welfare-improving market interventions. Finally, I began this paper by noting that every conversion petition is unique; the analyses of CareFirst, the mid-Atlantic markets in which it operates, and the arguments in support of or against conversion cannot necessarily be generalized to health plans petitioning for conversion in other markets. The framework exposited in this paper is entirely general, however, and I hope that it will make a contribution to those charged with the challenging tasks of analyzing and evaluating the complex public policy issues surrounding health plan conversions.

\section{Notes}

An earlier version of this paper was presented at the NBER 2003 Frontiers in Health Policy Research Conference that took place in Washington, D.C., in June 2003. The research for this paper was funded in part by the D.C. Appleseed Center for Law and Justice, a public advocacy organization that became a formal party to the official conversion proceedings of the Blue Cross and Blue Shield plan, CareFirst Inc. I am grateful to Richard Herzog, Walter Smith, Richard Meyer, Jack Needleman, and participants in the NBER 2003 Frontiers in Health Policy Research Conference for helpful comments and conversations.

1. Standard \& Poor's Ratings Direct, Research Report: Blues Convert to For-Profits to Compete, November 12, 2002.

2. Quoted in Blackstone, Erwin A., and Joseph P. Fuhr (1998). "Blue Cross: Health Insurance," in David I. Rosenbaum, (ed.), Market Dominance, Westport, Conn.: Praeger Publishers, 179-180.

3. Blackstone and Fuhr (1998). "Blue Cross: Health Insurance."

4. Most BCBS plans convert to a public-stock company as a step toward merging with or being acquired by another BCBS plan; the existence of publicly traded stock facilitates the ownership transfer and combination.

5. One of the association's bylaws requires that the use of the BCBS trademark can be acquired only by another BCBS plan.

6. The financial proceeds from the conversion and sale or initial public offering of a BCBS plan do not always endow a public trust or charitable foundation. James Robinson describes the factors that led the state government to benefit financially from the conversion of Empire Blue Cross and Blue Shield of New York ("The Curious Conversion of Empire Blue Cross," Health Affairs, 22(4):100-118, July/August 2003). 
7. A recent Supreme Court ruling upheld so-called any willing provider laws enacted at the state level that require health maintenance organizations to accept any qualified doctors who want to join the HMO's provider network ("Justices: States Can Force HMOs to Open Networks, " by Bill Mears, CNN.com, April 2, 2003).

8. "Community Impact Analysis of the Proposed Conversion of CareFirst, Inc.," a report produced by Accenture for CareFirst Blue Cross Blue Shield, January 2002.

9. Robinson, James, "The Curious Conversion of Empire Blue Cross."

10. Testimony of William L. Jews to the Maryland Insurance Administration, March 11, 2002.

11. Independent valuations of CareFirst by Richard Meyer, The Blackstone Group, and Cain Brothers found Wellpoint's offer to fall below their assessments of fair market valuation. (see Baltimore Sun article by M. William Salganik)

12. These enrollment data are drawn from the mandatory reports filed with the Insurance Commissioner's Office by health plans licensed to do business in the District of Columbia and from the national databases assembled by InterStudy. The InterStudy data are limited for the purpose of examining total health plan enrollment (HMO and non-HMO) in the following manner. While InterStudy is recognized as the leading source of data on health plans offering HMO products, the universe of plans in thesedata excludes health plans that do not offer an HMO product, but it includes data on nonHMO products for health plans that also offer an HMO. Hence, the sample of health plans in InterStudy is incomplete in its inclusion of purely non-HMO plans.

13. These enrollment and market share data were obtained from the health plan filings with the D.C. Insurance Commissioners Office, except for the enrollment data for the Federal Employees Health Benefits Program (FEHBP). The form filed with the Insurance Commissioner's Office does not list FEHBP enrollment, but it does list the total premiums collected by the plan for this product. The InterStudy database contains data on FEHBP enrollment for nearly all of the health plans operating in D.C. The CareFirst plan operating under the name of Group Hospitalization and Medical Services, Inc. (GHMSI) does not offer an HMO product and is therefore not included in the InterStudy database. FEHBP enrollment for GHMSI was imputed in the following manner. Using the premium data from the D.C. Insurance Commissioner's Office filings and enrollment data from InterStudy, I computed the average FEHBP premium for all health plans offering an FEHBP plan in D.C., except for GHMSI. I then imputed FEHBP enrollment for GHMSI by dividing its total FEHBP premiums by the average FEHBP premium in D.C.

14. Managed -care companies may transfer some of this risk to health care providers through contracts that involve prospective payment (i.e., capitation).

15. The data on health plan enrollment by product type was taken from health plan filings with the D.C. Insurance Commissioner's Office. These data are aggregated at the health plan level, and geographical breakdowns were not available (e.g., the number of GHMSI PPO enrollees in the District of Columbia). Furthermore, FEHBP enrollment was not included in these data. With the exception of GHMSI, it appears that all of the FEHBP health plans offered in D.C. are HMO plans.

16. Recall that the sample of plans included in the InterStudy database is defined by any plan offering an HMO product (hence, GHMSI is not included in the InterStudy database). Once GHMSI is included in the sample, however, InterStudy reports enrollment in all types of products (not just HMO products). Because of the sample selection, InterStudy may underestimate enrollment in non-HMO products. 
17. This is true only to the extent that local health plan enrollment is independent of (not correlated with) total regional or national enrollment.

18. See Himmelstein et al. (1999) and Landon et al. (2001).

19. I was originally hired as a consultant by D.C. Appleseed to examine the potential consequences of CareFirst converting to stock ownership and being acquired by Wellpoint. Not until the formal conversion proceedings were well underway did it become clear to me that issues of viability and governance structures would play a central role in the decision calculus of policy makers and regulatory officials.

\section{References}

Accenture (2002). "Community Impact Analysis of the Proposed Conversion of CareFirst, Inc." (A report produced for the board of CareFirst BlueCross BlueShield).

Blackstone, Erwin A. and Joseph P. Fuhr (1998). "Blue Cross: Health Insurance," in David I. Rosenberg (ed.) Market Dominance. Westport, CT: Praeger Publishers, 179-180.

Himmelstein, D.U., S Woolhandler, I. Hellander, and S.M. Wolfe (1999). "Quality of Care in Investor-Owned vs. Not-for-Profit HMOs," Journal of the American Medical Association 282(2):159-163.

Interstudy Competitive Edge 9.2 and 12.1

Landon, B., A. Zaslavsky, N. D. Beaulieu, J. Shaul, and P. Cleary (2001). "Health Plan Characteristics and Consumers' Assessments of Quality," Health Affairs 20(2): 274-286.

Mears, Bill (2003). "Justices: States can force HMOs to open networks." Available at www.CNN.com. (Accessed on April 2, 2003).

National Committee for Quality Assurance (2000). Quality Compass. Washington, D.C.

Robinson, James (2003). "The Curious Conversion of Empire Blue Cross," Health Affairs, 22(4):100-118.

Salganik, M. W. (2003). "Group values CareFirst at \$2.27B," Baltimore Sun, March 4.

Standard \& Poor's Ratings Direct (2002). Research Report: Blues Convert to For-Profits to Compete, November 12. 